\title{
The taxonomy, host range and pathogenicity of coronaviruses and other viruses in the Nidovirales order
}

\author{
Zhijian Zhou, Ye Qiu* and Xingyi Ge*
}

\begin{abstract}
The frequent emergence of coronavirus ( $\mathrm{CoV}$ ) epidemics has seriously threatened public health and stock farming. The major hosts for CoVs are birds and mammals. Although most CoVs inhabit their specific natural hosts, some may occasionally cross the host barrier to infect livestock and even people, causing a variety of diseases. Since the beginning of the new century, increasing attention has been given to research on CoVs due to the emergence of highly pathogenic and genetically diverse CoVs that have caused several epidemics, including the recent COVID-19 pandemic. Covs belong to the Coronaviridae family of the Nidovirales order. Recently, advanced techniques for viral detection and viral genome analyses have enabled characterization of many new nidoviruses than ever and have greatly expanded the Nidovirales order with new classification and nomenclature. Here, we first provide an overview of the latest research progress in the classification of the Nidovirales order and then introduce the host range, genetic variation, genomic pattern and pathogenic features of epidemic Covs and other epidemic viruses. This information will promote understanding of the phylogenetic relationship and infectious transmission of various pathogenic nidoviruses, including epidemic CoVs, which will benefit virological research and viral disease control.
\end{abstract}

Keywords: Coronavirus, Nidovirales, Hosts, S protein, Genetics, Evolution

\section{Introduction}

The ongoing coronavirus disease 2019 (COVID-19) pandemic caused by severe acute respiratory syndrome coronavirus 2 (SARS-CoV-2) has been prevalent in almost all regions of the world, resulting in 129,471,273 confirmed cases and 2,825,407 deaths by April 1, 2021. COVID-19 was declared as a worldwide pandemic on February 20, 2020 (WHO n.d.). During the last two decades, 5 types of coronaviruses $(\mathrm{CoV})$ have been found to infect humans, including SARS-CoV (2003) (Falsey and Walsh 2003), human coronavirus NL63 (HCoVNL63, 2004) (van der Hoek et al. 2004), human coronavirus HKU1 (HCoV-HKU1, 2005) (Woo et al. 2005),

\footnotetext{
* Correspondence: qiuye@hnu.edu.cn; xyge@hnu.edu.cn

Hunan Provincial Key Laboratory of Medical Virology, Institute of Pathogen Biology and Immunology, College of Biology, Hunan University, 27 Tianma Rd., Changsha, Hunan, China
}

Middle East Respiratory Syndrome Coronavirus (MERSCoV, 2012) (Zaki et al. 2012), and SARS-CoV-2 (2019) (Zhu et al. 2020), among which SARS-CoV, MERS-CoV, and SARS-CoV-2 are highly pathogenic CoVs. Together with 2 human CoVs (HCoV-229E and HCoV-OC43) discovered in the 1960s, 7 types of CoVs have been found to infect humans to date (Vetterlein and Hesse 1965; McIntosh et al. 1967). The frequent global CoV pandemics in the new century have alarmed experts and indicated the great threat of pathogenic CoVs to public health worldwide.

In addition to human CoVs, many animal CoVs also cause diseases in domestic animals and serious harm to livestock farming. For example, porcine $\mathrm{CoVs}$ are common porcine pathogens, including transmissible gastroenteritis virus (TGEV) (Doyle and Hutchings 1946), porcine respiratory coronavirus (PRCV, Chen et al. 
2019), porcine epidemic diarrhea virus (PEDV, Pensaert and Bouck 1978), porcine deltacoronavirus (PDCoV, Woo et al. 2012), porcine hemagglutinating encephalomyelitis virus (PHEV), and porcine enteric alphacoronavirus (PEAV), also known as swine acute diarrhea syndrome coronavirus (SADS-CoV, Gong et al. 2017; Pan et al. 2017; Zhou et al. 2018). In addition to porcine CoVs, there are CoVs that infect other livestock and animals, such as bovine coronavirus (BCoV, Castells et al. 2017), equine coronavirus (ECoV, Pusterla et al. 2016), canine coronavirus (CCoV, Decaro et al. 2010), and feline coronavirus (FCoV, Li et al. 2019). Furthermore, some avian CoVs, such as infectious bronchitis virus (IBV) and the closely related turkey coronavirus (TCoV) (Jackwood et al. 2012; Brown et al. 2016) cause diseases in poultry.

After the SARS-CoV epidemic in 2003, studies tracing epidemic CoVs revealed the extensive presence of nonpathogenic CoVs with remarkable genetic diversity in many species of wild animals. The natural hosts of these CoVs include bats, rodents, cats, wild birds, marine mammals and so on (Woo et al. 2012; Ge et al. 2013; Ge et al. 2017; Hu et al. 2017). According to genomic sequencing and phylogenetic analyses, most human CoVs have been shown to originate from wild animals at different time points and through different paths (Cui et al. 2019; Zhou et al. 2020b). It's particularly noteworthy that the 3 highly pathogenic CoVs, including SARS-CoV, MERS$\mathrm{CoV}$ and SARS-CoV-2, may originate from bats (Ge et al. 2013; Azhar et al. 2014; Wang et al. 2014b; Zhou et al. 2020b). The HKU-2-related bat coronavirus, named PEAV/SADS-CoV, was recently transmitted from bats to swine and caused an epidemic in 2016-17 (Zhou et al. 2018). On the other hand, the long-term persistence and rapid mutagenesis of native CoVs may lead to the emergence of new types of epidemic CoVs, which has brought many challenges to the prevention and control of these diseases. For example, epidemiological studies have shown an increasing genotype diversity of PEDV in pigs and IBV in poultry (Zhou et al. 2014; Li et al. 2017; Zeng et al. 2017). At the same time, the diversity and evolution of CoVs in their natural reservoirs, such as bats and birds, have also caused increasing concerns about their potential for interspecific transmission and to cause epidemics (Hu et al. 2017).

CoVs are membrane-enveloped viruses with a linear, single-stranded and positive RNA genome. CoVs belong to the Orthocoronavirinae subfamily of the Coronaviridae family in the Cornidovirineae suborder of the Nidovirales order (https://talk.ictvonline.org/taxonomy/) (Walker et al. 2019). After the SARS epidemic in 2003, a large number of CoVs with high genetic diversity were identified in various natural hosts of birds and mammals that could not be classified using the former taxonomic system. Thus, the system for CoV classification has been adjusted several times, and the latest version was proposed (International Committee on Taxonomy of Viruses Executive 2020). In addition, the widespread nature of CoVs raises concerns about the spread, spillover and prevalence of epidemic viruses in the future, which may impose significant respiratory and/or gastrointestinal diseases on humans and economic losses to livestock farming. Therefore, it is critical to investigate the characteristics of transmission and infection of CoVs. In this review, we provide an overview of the latest classification of viruses in the Nidovirales order and then focus on the genetic evolution, pathogenesis, and cross-species transmission of epidemic CoVs and other epidemic nidoviruses, aiming to provide a comprehensive understanding of the current progress of studies concerning CoVs and nidoviruses.

To avoid any divergence, information about the viruses listed in this review is preferentially in accordance with the latest update in the taxonomy system of the International Committee on Taxonomy of Viruses Executive on Taxonomy of Viruses (ICTV) (https://talk.ictvonline. org/taxonomy/), if available, which may not be completely consistent with the description of the original literature. At the same time, only the classified virus strains listed on the ICTV website are involved, while some virus strains reported elsewhere may not be mentioned. In addition, at present, the origin and spread of nidoviruses are still controversial topics, and some descriptions in this review may represent the authors' personal views only.

\section{Summary of the Nidovirales order Taxonomy of the Nidovirales order}

The Nidovirales order was first proposed by ICTV in 1996 and was named after the Latin term nido, which means "nest" (Pringle 1996). Initially, the order contained only 2 viral families, Coronaviridae and Arteriviridae (Pringle 1996). However, with improvements in techniques of virus detection and viral metagenomics, additional viral genomes have been detected (Ge et al. 2012; Shi et al. 2018). Characterization of these novel viral genomes has profoundly changed the classification of viruses. At present, 8 suborders have been established under the Nidovirales order: Abnidovirineae, Arnidovirineae, Cornidovirineae, Mesnidovirineae, Monidovirineae, Nanidovirineae, Ronidovirineae, and Tornidovirineae (Walker et al. 2019). These 8 suborders contain 14 viral families, 25 subfamilies, 39 genera, 65 subgenera, and a total of 109 viral species (Tables 1, 2 and 3). Genetic relationship among the 109 representative virus species is shown in Fig. 1. 
Table 1 Hosts and sampled countries for Cornidovirineae viruses

\begin{tabular}{|c|c|c|c|c|}
\hline Subfamily & Genus & Subgenus & Host & Country \\
\hline Letovirinae & Alphaletovirus & Milecovirus & Microhyla fissipes & Unknown \\
\hline \multirow[t]{25}{*}{ Orthocoronavirinae } & \multirow{14}{*}{$\begin{array}{l}\text { Alpha- } \\
\text { coronavirus }\end{array}$} & Colacovirus & Bat & USA, Canada \\
\hline & & Decacovirus & Bat & China \\
\hline & & Duvinacovirus & Homo sapiens, Camel, Bat & $\begin{array}{l}\text { USA, Netherlands, Italy, Sweden, Ghana, Saudi } \\
\text { Arabia, Germany, Kenya, Haiti, United Arab Emirates }\end{array}$ \\
\hline & & Luchacovirus & Rat & China, United Kingdom \\
\hline & & Minacovirus & Mink, Neovison vison & USA, Netherlands, Japan, China, Denmark \\
\hline & & Minunacovirus & Bat & China \\
\hline & & Myotacovirus & Myotis ricketti & China \\
\hline & & Nyctacovirus & Bat & China, Italy \\
\hline & & Pedacovirus & Sus scrofa & $\begin{array}{l}\text { China, South Korea, USA, Mexico, Viet Nam, Canada, } \\
\text { Ukraine, Belgium, France, Italy, Thailand, Viet Nam, } \\
\text { Slovenia, Colombia, United Kingdom, Hungary, } \\
\text { Japan, Germany, Russia, Philippines, Spain }\end{array}$ \\
\hline & & Rhinacovirus & Bat, Sus scrofa & China \\
\hline & & Setracovirus & Homo sapiens & Netherlands, USA, China, Haiti, Kenya, South Korea \\
\hline & & Soracovirus & Sorex araneus & China \\
\hline & & Sunacovirus & Suncus murinus & China \\
\hline & & Tegacovirus & Sus scrofa, Dog, Cat & $\begin{array}{l}\text { USA, China, Italy, Netherlands, Germany, United } \\
\text { Kingdom, Belgium, Denmark, Mexico, Brazil, Spain }\end{array}$ \\
\hline & \multirow[t]{5}{*}{$\begin{array}{l}\text { Beta- } \\
\text { coronavirus }\end{array}$} & Embecovirus & $\begin{array}{l}\text { Homo sapiens, Bovine, Alpaca, Antelope, } \\
\text { Deer, Rat, Oryctolagus cuniculus, Dog, } \\
\text { Camel, Sus scrofa, Horse, Pan troglodytes } \\
\text { verus }\end{array}$ & $\begin{array}{l}\text { Japan, Australia, USA, France, Belgium, China, } \\
\text { Germany, South Korea, United Arab Emirates, Saudi } \\
\text { Arabia, United Kingdom, Bangladesh, Mexico, } \\
\text { Malaysia, Cote d'Ivoire, Uganda, Thailand, Kenya, } \\
\text { Ethiopia, Morocco, Nigeria }\end{array}$ \\
\hline & & Hibecovirus & Bat & Nigeria, China \\
\hline & & Merbecovirus & $\begin{array}{l}\text { Bat, Homo sapiens, Camel, Hedgehog, } \\
\text { Lama glama }\end{array}$ & $\begin{array}{l}\text { China, United Kingdom, Germany, Jordan, South } \\
\text { Africa, Saudi Arabia, United Arab Emirates, France, } \\
\text { Qatar, Egypt, USA, South Korea, Oman, Thailand, } \\
\text { Italy, Ethiopia, Morocco, Burkina Faso, Nigeria, } \\
\text { Kenya }\end{array}$ \\
\hline & & Nobecovirus & Bat & China, India, Singapore, Cameroon \\
\hline & & Sarbecovirus & $\begin{array}{l}\text { Bat, Civet, Homo sapiens, Malayan } \\
\text { pangolin, Felis catus, Mink, Dog, Tiger }\end{array}$ & Global \\
\hline & \multirow{3}{*}{$\begin{array}{l}\text { Delta- } \\
\text { coronavirus }\end{array}$} & Andecovirus & Wigeon & China \\
\hline & & Buldecovirus & Sus scrofa, Birds, Leopard cat & $\begin{array}{l}\text { USA, South Korea, China, Thailand, Laos, Viet Nam, } \\
\text { Japan, United Arab Emirates, Poland, Australia }\end{array}$ \\
\hline & & Herdecovirus & Night-heron & China \\
\hline & \multirow{3}{*}{$\begin{array}{l}\text { Gamma- } \\
\text { coronavirus }\end{array}$} & Brangacovirus & Branta canadensis & Canada \\
\hline & & Cegacovirus & Delphinapterus leucas, Bottlenose dolphin & USA \\
\hline & & Igacovirus & $\begin{array}{l}\text { Chicken, Turkey, Duck, Pheasant, Goose, } \\
\text { Partridge, Pigeon, Peafowl }\end{array}$ & $\begin{array}{l}\text { China, USA, Canada, Netherlands, Nigeria, Sweden, } \\
\text { South Korea, Australia, Ukraine, South Africa, Italy, } \\
\text { Belgium, France, India, Poland, Brazil, Sudan, Jordan, } \\
\text { Pakistan, Egypt, United Kingdom, Uruguay, Iran, } \\
\text { Malaysia, Peru, Australia, Norway }\end{array}$ \\
\hline
\end{tabular}

Notes: Some related but unclassified viruses are not listed

\section{Common features of viruses in the Nidovirales order}

Members of the Nidovirales order are membraneenveloped viruses with a single strand positive RNA genome. Although the viral particle size, morphology, and genome size of viruses in these 8 suborders vary greatly, nidoviruses share some significant common features. The most typical feature is transcription of multiple 3'-nested subgenomic RNAs from the 5' terminus to the 3 ' terminus along the genome during viral gene expression, which endows the order name of nido-"nest" 
Table 2 Hosts and sampled countries of Arnidovirineae viruses

\begin{tabular}{|c|c|c|c|c|c|}
\hline Family & Subfamily & Genus & Subgenus & Host & Country \\
\hline \multirow[t]{19}{*}{ Arteriviridae } & Crocarterivirinae & Muarterivirus & Muarterivirus afrigant & Crocidura olivieri guineensis & Guinea \\
\hline & Equarterivirinae & Alphaarterivirus & Alphaarterivirus equid & Horse, Donkey & $\begin{array}{l}\text { USA, France, United Kingdom, Chile, } \\
\text { Serbia, Poland }\end{array}$ \\
\hline & Heroarterivirinae & Lambdaarterivirus & $\begin{array}{l}\text { Lambdaarterivirus } \\
\text { afriporav }\end{array}$ & Cricetomys emini & Cameroon \\
\hline & Simarterivirinae & Deltaarterivirus & Hedartevirus & Monkey & USA \\
\hline & & Epsilonarterivirus & Sheartevirus & Monkey & USSR, South Africa \\
\hline & & Etaarterivirus & Etaarterivirus ugarco 1 & Monkey & Uganda \\
\hline & & lotaarterivirus & Debiartevirus & Monkey & Cameroon \\
\hline & & & Kigiartevirus & Monkey & Uganda \\
\hline & & & Pedartevirus & Monkey & USA \\
\hline & & Thetaarterivirus & Kaftartevirus & Monkey, Papio & Zambia \\
\hline & & & Mitartevirus & Papio & Tanzania \\
\hline & & Zetaarterivirus & $\begin{array}{l}\text { Zeta-arterivirus ugarco } \\
1\end{array}$ & Monkey & Uganda \\
\hline & Variarterivirinae & Betaarterivirus & Ampobartevirus & Sus scrofa & USA, South Korea, India, China \\
\hline & & & Chibartevirus & $\begin{array}{l}\text { Myodes rufocanus, } \\
\text { Eothenomys inez }\end{array}$ & China \\
\hline & & & Eurpobartevirus & Sus scrofa & $\begin{array}{l}\text { Netherlands, France, Hungary, China, } \\
\text { Russia }\end{array}$ \\
\hline & & & Micartevirus & Neodon clarkei & China \\
\hline & & Gammaarterivirus & $\begin{array}{l}\text { Gammaarterivirus } \\
\text { lacdeh }\end{array}$ & Rat & Unknown \\
\hline & & Nuarterivirus & Nuarterivirus guemel & Chinchilla lanigera & China \\
\hline & Zealarterivirinae & Kappaarterivirus & $\begin{array}{l}\text { Kappaarterivirus } \\
\text { wobum }\end{array}$ & Trichosurus vulpecula & Australia, New Zealand \\
\hline Cremegaviridae & Rodepovirinae & Pontunivirus & Chinturpovirus 1 & Mauremys megalocephala & China \\
\hline Gresnaviridae & Reternivirinae & Cyclophivirus & Ptyasnivirus 1 & Cyclophiops major & China \\
\hline Olifoviridae & Gofosavirinae & Kukrinivirus & $\begin{array}{l}\text { Oligodon snake } \\
\text { nidovirus } 1\end{array}$ & Oligodon formosanus & China \\
\hline
\end{tabular}

Notes: Some related but unclassified viruses are not listed

(Posthuma et al. 2006). The other common features include similar genomic organization (encoding the nonstructural polyprotein upstream and the structural protein downstream of the genome), expression of the polyprotein by ribosomal frame shifting mode, and some nonstructural proteins (NSPs) with unique protease activities (Fig. 2) (Posthuma et al. 2008). Due to the complexity of the genome, the new classification standard of order Nidovirales is based on amino acid (aa) sequences of several hallmark genes only, which include 3CLpro (3C-like protease), NiRAN (nidovirus RdRp-associated nucleotidyltransferase), RdRp (RNA-directed RNA polymerase), ZBD (Zn-binding domain covalently linked to HEL1), and HEL1 (helicase of superfamily 1) domains of the replicase protein (International Committee on Taxonomy of Viruses Executive 2020). Domains of
3CLpro, NiRAN, RdRp, ZBD, and HEL1 located in the genome and proteins are illustrated in Fig. 2 using the SARS-CoV-2 model.

\section{The taxonomy, host range and pathogenicity of Cornidovirineae}

Suborder Cornidovirineae

Among all 8 suborders of the Nidovirales order, Cornidovirineae harbors the most epidemic viruses. Currently, the Cornidovirineae suborder contains 1 viral family, Coronaviridae, which is further divided into 2 subfamilies, Letovirinae and Orthocoronavirinae (Bukhari et al. 2018). The subfamily Letovirinae contains 1 genus Alphaletovirus, 1 subgenus Milecovirus, and 1 species Microhyla letovirus 1 (MLeV), which is represented by a $22.3 \mathrm{~kb}$ potentially partial genome found in an ornamented pygmy frog (Microhyla 
Table 3 Hosts and sampled countries of Ab-, Mes-, Mo-, Na-, Ro- and Tor-Nidovirineae viruses

\begin{tabular}{|c|c|c|c|c|c|c|}
\hline Suborders & Family & Subfamily & Genus & Subgenus & Host & Country \\
\hline Abnidovirineae & Abyssoviridae & Tiamatvirinae & Alphaabyssovirus & Aplyccavirus & Aplysia californica & Unknown \\
\hline \multirow[t]{10}{*}{ Mesnidovirineae } & Medioniviridae & Medionivirinae & Turrinivirus & Beturrivirus & Turritella sea snails & China \\
\hline & & Tunicanivirinae & Bolenivirus & Balbicanovirus & Botrylloides leachii & New Zealand \\
\hline & Mesoniviridae & Hexponivirinae & Alphamesonivirus & Casualivirus & $\begin{array}{l}\text { Coquillettidia } \\
\text { xanthogaster }\end{array}$ & Australia \\
\hline & & & & Enselivirus & Culex & Cote d'Ivoire \\
\hline & & & & Hanalivirus & Culex & Cote d'Ivoire \\
\hline & & & & Kadilivirus & Culex & Brazil \\
\hline & & & & Karsalivirus & Culex & Viet Nam, Indonesia \\
\hline & & & & Menolivirus & Uranotaenia & Cote d'Ivoire \\
\hline & & & & Namcalivirus & $\begin{array}{l}\text { Aedes, Rat, Culex, } \\
\text { Uranotaenia }\end{array}$ & $\begin{array}{l}\text { Viet Nam, Cote d'Ivoire, Indonesia, } \\
\text { Thailand, China, South Korea, } \\
\text { Senegal, Ghana, Australia, Italy, } \\
\text { USA, Austria, Mexico, Sweden, } \\
\text { Brazil, Spain }\end{array}$ \\
\hline & & & & Ofalivirus & Mansonia & Brazil \\
\hline Monidovirineae & Mononiviridae & Mononivirinae & Alphamononivirus & Dumedivirus & $\begin{array}{l}\text { Schmidtea } \\
\text { mediterranea }\end{array}$ & USA \\
\hline \multirow[t]{2}{*}{ Nanidovirineae } & Nanghoshaviridae & Chimanivirinae & Chimshavirus & Nangarvirus 1 & Chimaera sp. & China \\
\hline & Nanhypoviridae & Hyporhamsavirinae & Sajorinivirus & $\begin{array}{l}\text { Halfbeak } \\
\text { nidovirus } 1\end{array}$ & $\begin{array}{l}\text { Hyporhamphus } \\
\text { sajori }\end{array}$ & China \\
\hline \multirow[t]{4}{*}{ Ronidovirineae } & Euroniviridae & Ceronivirinae & Charybnivirus & Cradenivirus & Charybdis crab & China \\
\hline & & & & Wenilivirus & Crustacean & China \\
\hline & & Crustonivirinae & Paguronivirus & Behecravirus & Hermit crab & China \\
\hline & Roniviridae & Okanivirinae & Okavirus & Tipravirus & Penaeus & Australia, Thailand, Egypt, China \\
\hline \multirow[t]{13}{*}{ Tornidovirineae } & Tobaniviridae & Piscanivirinae & Bafinivirus & Blicbavirus & Blicca bjoerkna & Germany \\
\hline & & & & Pimfabavirus & Pimephales promelas & USA \\
\hline & & & & $\begin{array}{l}\text { unclassified } \\
\text { Bafinivirus }\end{array}$ & $\begin{array}{l}\text { Salmo salar, Yellow } \\
\text { catfish }\end{array}$ & Canada, China \\
\hline & & & Oncotshavirus & Salnivirus & $\begin{array}{l}\text { Oncorhynchus } \\
\text { tshawytscha, } \\
\text { Macrognathus } \\
\text { aculeatus, Crucian } \\
\text { carp, Carassius } \\
\text { auratus }\end{array}$ & Canada, China, United Kingdom \\
\hline & & Remotovirinae & Bostovirus & Bosnitovirus & Cattle & USA \\
\hline & & Serpentovirinae & Infratovirus & Hepoptovirus & Hebius popei & China \\
\hline & & & & Xintolivirus & $\begin{array}{l}\text { Snake-associated } \\
\text { nematodes }\end{array}$ & China \\
\hline & & & Lyctovirus & Rebatovirus & Lycodon rufozonatus & China \\
\hline & & & Pregotovirus & Roypretovirus & $\begin{array}{l}\text { Python regius, } \\
\text { Morelia viridis }\end{array}$ & USA, Switzerland \\
\hline & & & & Snaturtovirus & Myuchelys georgesi & Australia \\
\hline & & & & Tilitovirus & Tiliqua rugosa & Australia \\
\hline & & & Sectovirus & Sanematovirus & $\begin{array}{l}\text { Snake-associated } \\
\text { nematodes }\end{array}$ & China \\
\hline & & Torovirinae & Torovirus & Renitovirus & $\begin{array}{l}\text { Sus scrofa, Cattle, } \\
\text { Horse }\end{array}$ & China, USA, Japan, Switzerland \\
\hline
\end{tabular}




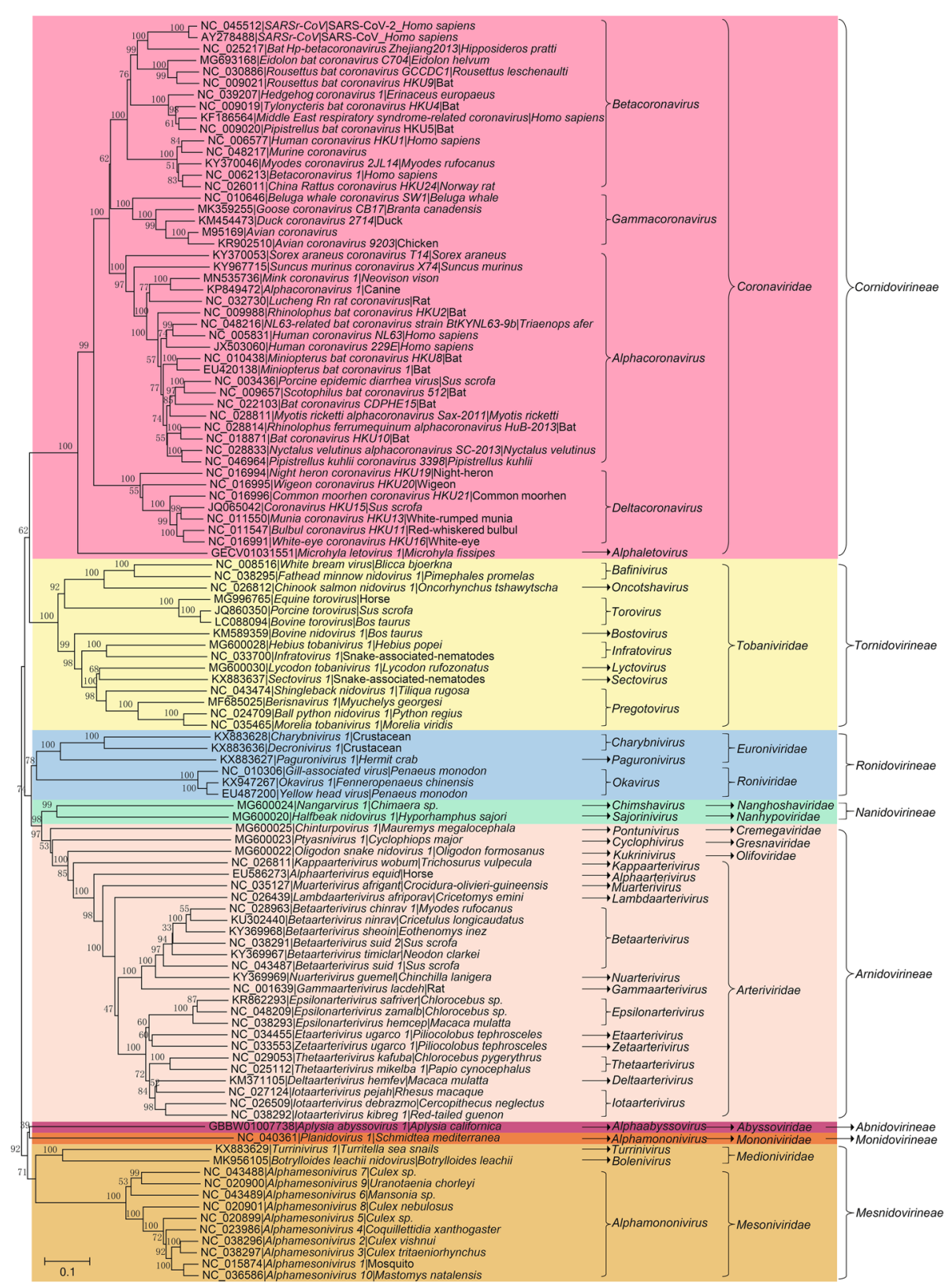

Fig. 1 Phylogenetic tree of RNA-dependent RNA polymerase (RdRp) amino acid sequences of 109 viral species in the Nidovirales order. The tree was constructed using the neighbor-joining method with a p-distance model and 1000 bootstraps in the MEGA V. 7.0.14

fissipes) (Bukhari et al. 2018). In contrast, the subfamily Orthocoronavirinae contains 4 genera, Alphacoronavirus (14 subgenera and 19 species), Betacoronavirus (5 subgenera and 14 species), Deltacoronavirus (3 subgenera and 7 species), and Gammacoronavirus (3 subgenera and 5 species), which is the largest subfamily in the Nidovirales order, including some highly pathogenic viruses, such as SARS-CoV, MERS-CoV, and SARS-CoV-2 (Table 1)
(Coronaviridae Study Group of the International Committee on Taxonomy of Viruses 2020). In this review, "CoVs" refers to viruses of the subfamily Orthocoronavirinae (Figs. 2, 3, 4 and 5).

\section{Subfamily Orthocoronavirinae}

CoVs are spherical, enveloped viral particles (approximately $100 \mathrm{~nm}$ in diameter) with $\mathrm{S}$ proteins on the surface. The subfamily Orthocoronavirinae is divided into 4 


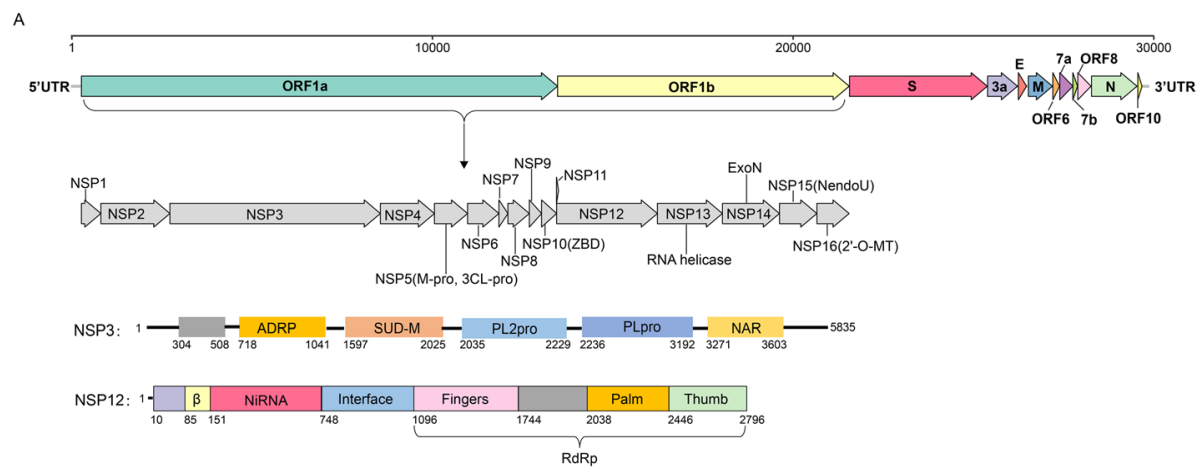

B

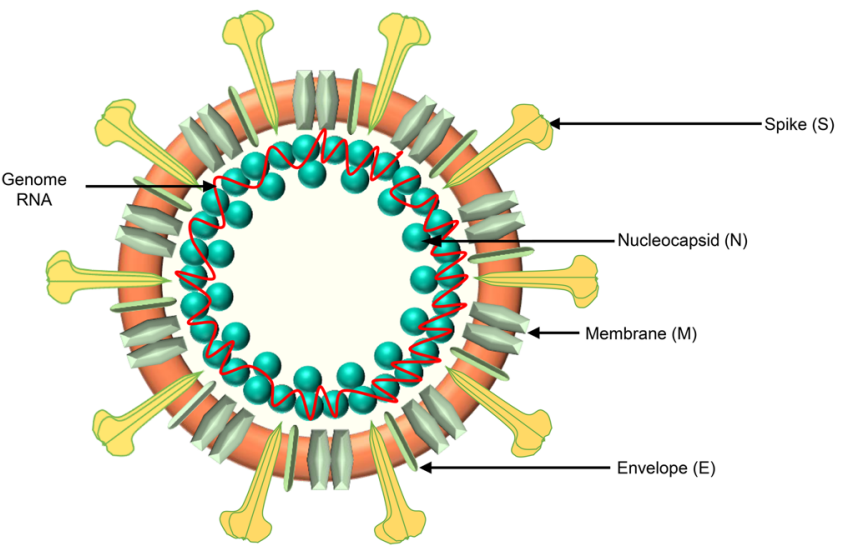

Fig. 2 Genome structure, coding proteins, and viral particle structure diagram of coronavirus represented by SARS-CoV-2. a Genome structure, functional domains and locations of SARS-CoV-2. NSP, nonstructural proteins; 3Clpro, 3C-like protease; NiRAN, nidovirus RdRp-associated nucleotidyltransferase; RdRp, RNA-directed RNA polymerase; ZBD, Zn-binding domain covalently linked to HEL1; HEL1, helicase of superfamily 1; NendoU, endonuclease; 2'-O-MT, 2'-O-methyltransferase; ExoN, 3'-5' exonuclease; SUD-M, SARS-unique domains; ADRP, ADP-ribose-1"phosphatase; PLpro, papain-like protease; NAR, nucleic acid-binding domain. b Viral particle diagram of SARS-CoV-2. Structural proteins of S, N, M, and $\mathrm{E}$ are labeled, and the red line indicates the RNA genome

genera: Alphacoronavirus (Alpha-CoV), Betacoronavirus (Beta-CoV), Deltacoronavirus (Delta-CoV), and Gammacoronavirus (Gamma-CoV) (Wong et al. 2019). AlphaCoVs and beta-CoVs infect mammals, while delta-CoVs and gamma-CoVs mostly infect birds, but a few of them do infect mammals (Woo et al. 2012). Currently, there are 14 subgenera (from Colacovirus to Tegacovirus), including 19 species in Alphacoronavirus with 5 subgenera (Embecovirus, Hibecovirus, Mergecovirus, Nobecovirus and Sarbecovirus), 14 species in Betacoronavirus with 3 subgenera (Andecovirus, Buldecovirus and Herdecovirus), 7 species in Deltacoronavirus with 3 subgenera (Brangacovirus, Cegacovirus, and Igacovirus), and 5 species in Gammacoronavirus (Table 1, Fig. 3).

\section{Alpha-CoVs}

\section{Human related alpha-CoVs}

Alpha-CoVs contain 14 viral genera and 19 species and are the largest genus in the subfamily Orthocoronavirinae (Fig. 3). Two human CoVs (HCoVs) in alpha-CoVs, HCoV-229E and HCoV-NL63, which belong to subgenera Duvinacovirus and Setracovirus, respectively, have been identified (McIntosh et al. 1967; van der Hoek et al. 2004). These CoVs are prevalent worldwide in children and adults and cause respiratory infections, usually leading to mild cold-like symptoms and acute respiratory disease (El-Sahly et al. 2000; van der Hoek et al. 2004). Genetic evidence has shown that HCoV-229E and NL63 share common ancestors with bat $\mathrm{CoVs}$, indicating the possibility of viral origin from bats (Tao et al. 2017). 229E-like bat CoVs, such as strains BtKY229E-1, BtKY229E-8 and BtCoV/FO1A-F2, have been detected in Hipposideros bats in Africa (Pfefferle et al. 2009; Crossley et al. 2012). Moreover, CoVs highly similar to $229 \mathrm{E}$ were also detected in camelids, including alpacas and dromedary camels (Crossley et al. 2012; Corman et al. 2016). The 229E-related CoVs isolated from dromedary camels can use human aminopeptidase N (APN) as a receptor and efficiently replicate in human hepatoma cells, which are neutralized by antibodies in human sera positive for 229E, suggesting a close genetic relationship between 229E and 229E-related CoVs (Corman 


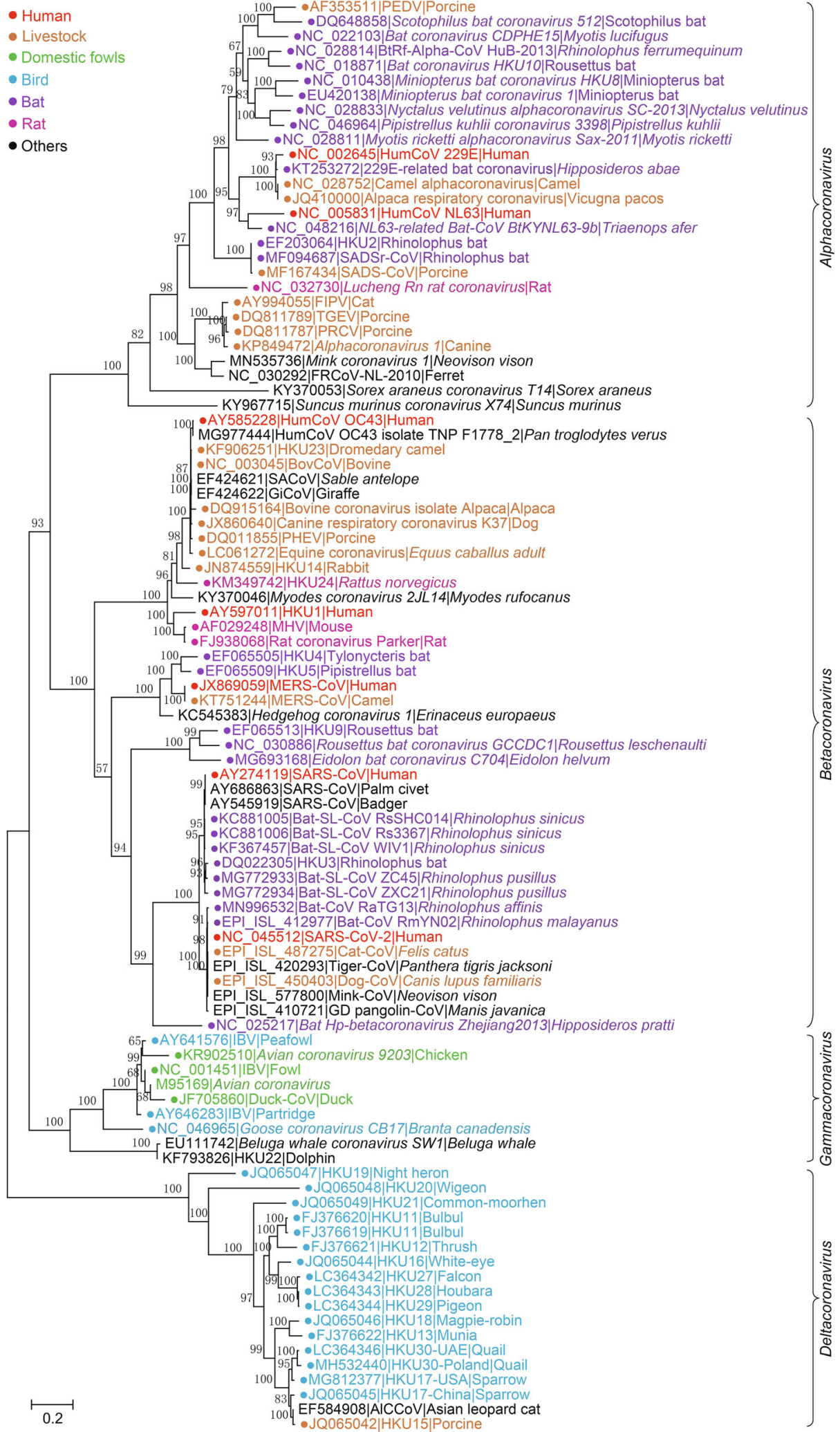

Fig. 3 The maximum likelihood tree of coronaviruses based on amino acid sequences of RdRp gene. The tree was constructed using an IQ-tree with 10,000 ultrafast bootstraps and the most appropriate substitution model of $\mathrm{LG}+\mathrm{F}+\mathrm{I}+\mathrm{G} 4$, which was calculated by ModelFinder 


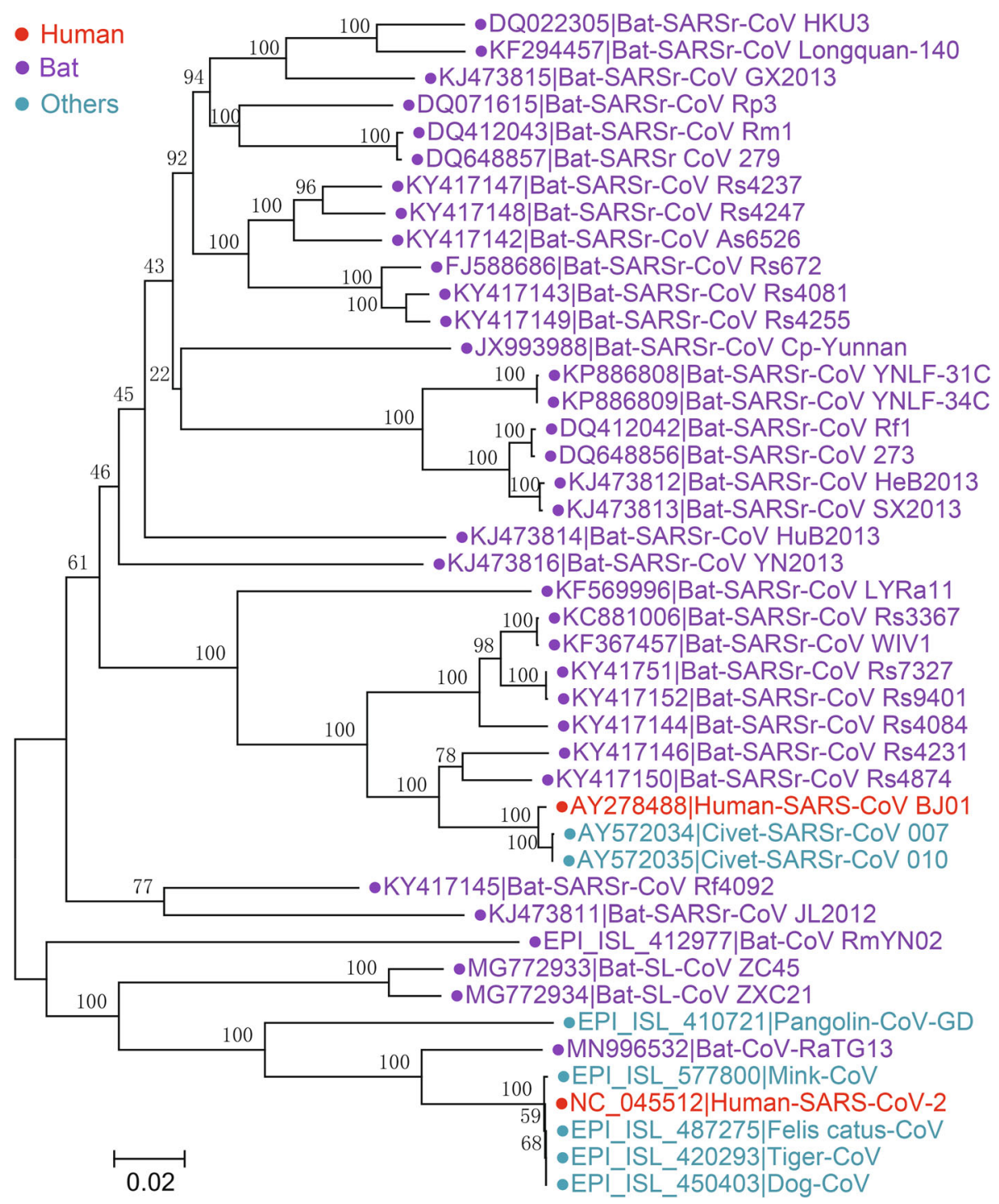

Fig. 4 The neighbor-joining tree of spike gene nucleotide sequences in Sarbecovirus. The tree was constructed using the p-distance model and 1000 bootstraps in the MEGA V. 7.0.14. Viral strains derived from humans, bats, and other animals are indicated by red, purple, and cyan, respectively

et al. 2016). Due to the long-term contact and habitat overlap between humans and camels, one of the conjectures about the transmission path of $229 \mathrm{E}$ is that the ancestor bat $\mathrm{CoV}$ was transmitted to camels first and then from camels to humans (Corman et al. 2016). Bat and camel 229E-related CoVs have been designated into the same species represented by $229 \mathrm{E}$ because all of these CoVs share more than 95\% amino acid (aa) sequence identity (higher than 92.4\% according to the species demarcation criteria), with $229 \mathrm{E}$ in the concatenated protein domains of 3CLpro, NiRAN, RdRp, ZBD and HEL1 (Sabir et al. 2016; International Committee on Taxonomy of Viruses
Executive 2020). NL63-like CoVs were also found in Triaenops bats, such as strains BtKYNL63-9a, BtKYNL63-9b, and BtKYNL63-15 (Tao et al. 2017). These NL63-like bat CoVs exhibited less than 90\% similarity in their aa sequences compared to NL63 in the concatenated protein domains of 3CLpro, NiRAN, RdRp, ZBD and HEL1, and thus, they were classified into NL63-related bat coronavirus strain BtKYNL63$9 b$ species, parallel to the human coronavirus NL63 species in the subgenus Setracovirus. However, NL63related CoVs have not yet been detected in livestock or other animals, so the origin and intermediate host(s) of NL63 are still unclear. Notably, NL63- 


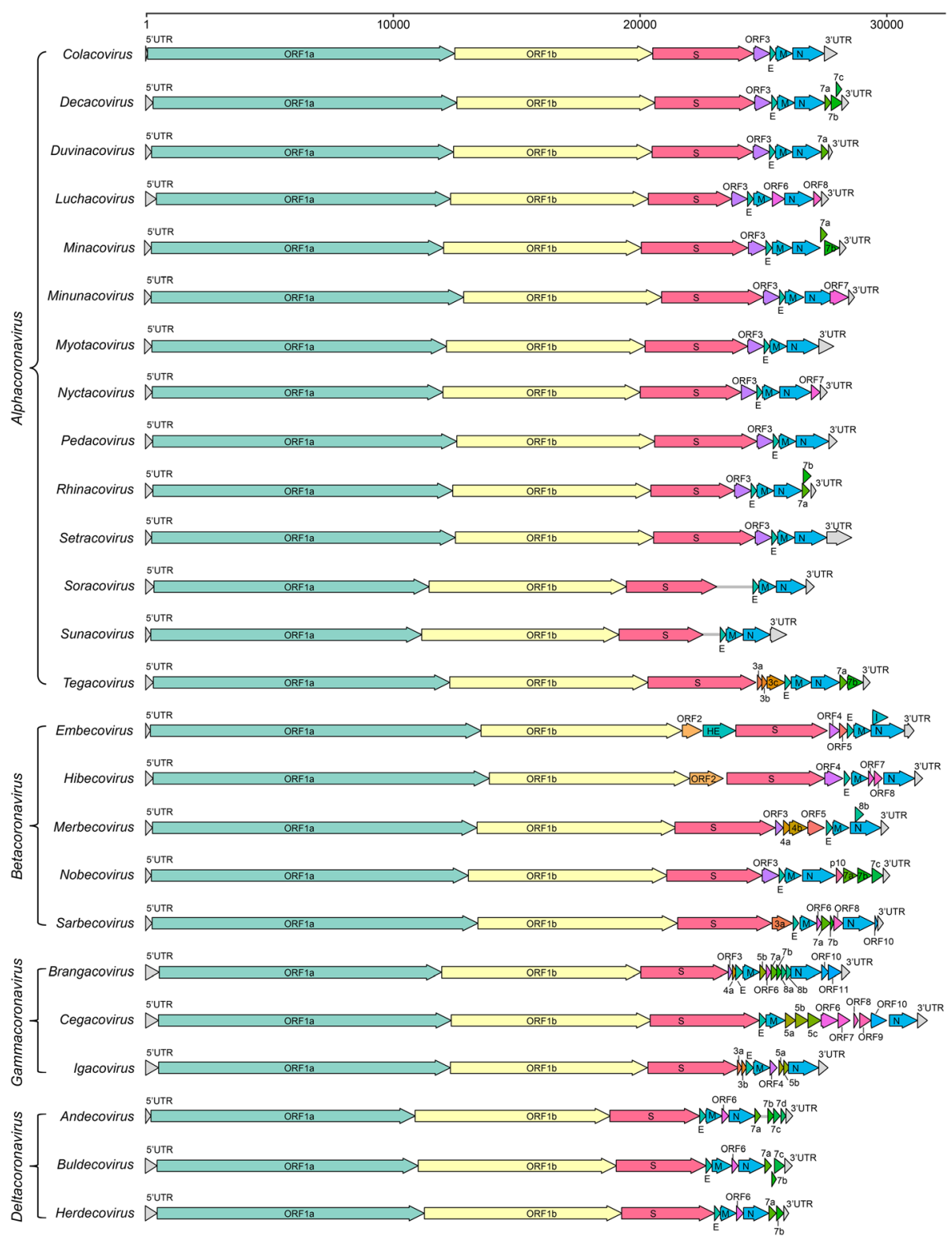

Fig. 5 Gene composition of 25 subgenera in 4 viral genera of Orthocoronavirinae. The reference strains used for mapping in each subgenus are as follows: Colacovirus (Bat-CoV CDPHE15/USA/2006, NC_022103.1), Decacovirus (Bat-CoV HKU10, NC_018871.1), Duvinacovirus (229E-related batCoV BtKY229E-1, KY073747.1), Luchacovirus (AcCoV-JC34, NC_034972.1), Minacovirus (FRCoV-NL-2010, NC_030292.1), Minunacovirus (Bat-CoV HKU8, NC_010438.1), Myotacovirus (BtMr-CoV/SAX2011, NC_028811.1), Nyctacovirus (Bat-CoV HKU33, MK720944.1), Pedacovirus (PEDV, NC_003436.1), Rhinacovirus (SADS-CoV, MT199592.1), Setracovirus (NL63-related bat-CoV BtKYNL63-9b, NC_048216.1), Soracovirus (Shrew-CoV/Tibet2014, KY370053.1), Sunacovirus (Wencheng Sm shrew CoV Xingguo-74, KY967715.1), Tegacovirus (CCoV/NTU336/F/2008, GQ477367.1), Embecovirus (Murine CoV, JX169867.1), Hibecovirus (Bat Hp-betacoronavirus/Zhejiang2013, NC_025217.1), Merbecovirus (Human MERS-CoV, NC_019843.3), Nobecovirus (Rousettus bat-CoV GCCDC1 356, NC_030886.1), Sarbecovirus (SARS-CoV-2, NC_045512.2), Brangacovirus (Canada goose CoV Cambridge_Bay_2017, MK359255.1), Cegacovirus (Beluga Whale CoV SW1, NC_010646.1), Igacovirus (Turkey CoV, NC_010800.1), Andecovirus (Wigeon CoV HKU20, NC_016995.1), Buldecovirus (Common-moorhen CoV HKU21, NC_016996.1), Herdecovirus (Night-heron CoV HKU19, NC_016994.1)

related and 229E-related bat CoVs exhibit high genetic diversity in bats, and recombination of bat CoVs may accelerate the occurrence of new viruses and the possibility of cross-species transmission (Tao et al. 2017).
Bat alpha-CoVs and derived CoVs infecting other animals Bats carry many different CoVs and have been recognized as important natural reservoirs for CoVs. Bat CoVs occupy 11 of 19 viral species in alpha-CoVs. The representative species of subgenus Colacovirus is bat 
coronavirus CDPHE15, which was identified in Myotis lucifugus (little brown bat) (Subudhi et al. 2017). The subgenus Decacovirus contains 2 species, bat coronavirus HKU10 and Rhinolophus ferrumequinum alphacoronavirus $\mathrm{HuB}-2013$, both of which were isolated from bats. HKU10- and HKU10-related CoVs were identified in 2 species of bats, Rousettus leschenaultii (Leschenault's Rousettes) and Hipposideros pomona (Pomona leaf-nosed bat), which were named Ro-BatCoV HKU10 and Hi-BatCoV HKU10, respectively (Lau et al. 2012). Ro-BatCoV HKU10 and Hi-BatCoV HKU10 share high aa similarity (>99\%) among 3CLpro, NiRAN, RdRp, ZBD and HEL1 but only $60.5 \%$ aa identity in the S proteins. Interspecies transmission of HKU10 from Leschenault's Rousettes to Pomona leaf-nosed bats, 2 different bat suborders, has been reported in a previous study (Lau et al. 2012). The HKU10-related bat $\mathrm{CoV}$ was also identified in Rhinolophus sinicus (Rs-BatCoV HKU32), which may be a potential novel species (Lau et al. 2019b). The species of Rhinolophus ferrumequinum alphacoronavirus $H u B-2013$ has several strains, among which the strain BtRf-Alpha-CoV/HuB2013 was detected in Rhinolophus ferrumequinum, and the strain BtMs- alpha-CoV/ GS2013 was detected in Myotis bats (Wu et al. 2016). The subgenus Minunacovirus includes 2 species, Miniopterus bat coronavirus 1 and Miniopterus bat coronavirus HKU8, which are common CoVs in Miniopterus bats, such as Miniopterus schreibersii, Miniopterus fuliginosus and Miniopterus pusillus (Chu et al. 2008; Wu et al. 2016).

The subgenus Myotacovirus contains 1 species, Myotis ricketti alphacoronavirus Sax-2011, which was found in Myotis ricketti in China in 2011 (Wu et al. 2016). The subgenus Nyctacovirus contains 2 species, Nyctalus velutinus alphacoronavirus SC-2013 (BtNv-Alpha-CoV/ SC2013) and Pipistrellus kuhlii coronavirus 3398 (BatCoV/P.kuhlii/Italy/3398), which were detected in Nyctalus and Pipistrellus bats, respectively (Wu et al. 2016; De Sabato et al. 2019). Recently, bat CoV HKU33 (Tr-BatCoV HKU33) was discovered in Tylonycteris robustula (greater bamboo bats) in Guizhou Province in China (Lau et al. 2019b). Tr-BatCoV HKU33 is most closely related to BtNv-alpha-CoV/SC2013. However, in the concatenated protein domains, aa sequence identity is 76.3\% between $\mathrm{Tr}$-BatCoV HKU33 and BtNv-AlphaCoV/SC2013, indicating that Tr-BatCoV HKU33 represents a novel $\mathrm{CoV}$ species and a potential novel subgenus (less than 14.7\% homology with the 3CLpro, NiRAN, RdRp, ZBD and HEL1 domains) in the alphaCoV genus (Lau et al. 2019b).

The subgenus Pedacovirus contains 2 species, PEDV and Scotophilus bat coronavirus 512 (BtCoV/512). BtCoV/512 was discovered in Scotophilus kuhlii bats in Hainan, China (Tang et al. 2006). PEDV is the etiologic agent of porcine epidemic diarrhea (PED), which infects pigs of all ages and causes significantly high mortality in piglets under 7 days old with symptoms including diarrhea, vomiting, anorexia and dehydration (Chen et al. 2013). Since the recognition of PEDV in 1978 in Belgium, this virus has caused epidemics worldwide and has continuously impaired pig farming industry (Pensaert and Bouck 1978). During long-term epidemics, novel PEDV variants continuously emerge, deriving the virulent variants of SINDEL groups and different genotype groups including GI and GII (even more groups or subgenotypes) (Zeng et al. 2017). In addition, the coexistence or coinfection of multiple genotypes or variants of PEDV has been reported, which makes the prevention and control of PEDV more difficult (Zeng et al. 2017).

The subgenus Rhinacovirus has 1 species, Rhinolophus bat coronavirus HKU2 (Bat-CoV HKU2). Bat-CoV HKU2 was first reported in 2006 and was detected in Rhinolophus sinicus (Chinese horseshoe bat) (Woo et al. 2006a). Subsequently, HKU2-like viruses were identified in other bat species, such as Rhinolophus ferrumequinum and Rhinolophus affinis (Lau et al. 2007; Wu et al. 2016). HKU2 is genetically distinct from other known bat alpha-CoVs and forms a unique phylogenetic lineage (Fig. 3) (Wu et al. 2016). Another remarkable feature of HKU2 is the shortest aa sequence of its $S$ protein, which has deletions in the $\mathrm{N}$-terminal region and extremely low $(<30 \%)$ aa identities with the other S proteins of CoVs (Lau et al. 2007). These significant differences indicate that HKU2 has a special evolutionary history. Because HKU2 has a long phylogenetic relationship with common alpha-CoV pathogens, it was not predicted to exhibit cross species transmission or lead to diseases until a similar virus was detected in piglets with diarrhea symptoms in China from 2016 to 2017 (Gong et al. 2017; Pan et al. 2017). In October 2016 and February 2017, outbreaks of newborn piglet diarrhea occurred in commercial pig farms in Guangdong Province, characterized by acute vomiting and watery diarrhea with a mortality rate over $35 \%$ in piglets (Pan et al. 2017). The etiology was identified as a Bat-HKU2 alpha-CoV called swine enteric alphacoronavirus (SeACoV), porcine enteric alphacoronavirus (PEAV), or SADS-CoV (Zhou et al. 2018). The genome sequence of SADS-CoV showed approximately $95 \%$ nucleotide (nt) identity with the Bat HKU2 strains (Pan et al. 2017). However, at the nt and aa levels, the S of SADS-CoV only exhibited approximately $80 \%$ and $86 \%$ sequence identities with that of bat HKU2 (Pan et al. 2017; Zhou et al. 2018). Recent studies showed that bat HKU2 strains derived from bats in Guangdong Province were genetically diverse in different Rhinolophus bats and exhibited different homologies to SADS-CoV, from $95.09 \%$ to $98.48 \%$ (Zhou et al. 2018). Virological, epidemiological, and evolutionary 
evidence suggested that SADS-CoV might have recently spread from bats to pigs and cause an outbreak of disease (Zhou et al. 2018). One study reported that SADS$\mathrm{CoV}$ caused an epidemic across 4 farms, leading to the death of 24,693 piglets from October 2016 to January 2017 (Zhou et al. 2018). After that, new SADS cases were reported in Fujian Province of China in 2018 until January 2019 (Yang et al. 2020b) and in Southern China in February 2019 (Zhou et al. 2019). Moreover, experimental results in different laboratories showed that SADS-CoV has broad cell tropism and can infect cells derived from bats, mice, rats, gerbils, hamsters, pigs, chickens, nonhuman primates, humans and certain primary human cells, including different primary human lung cell types and primary human intestinal cells (Yang et al. 2019; Edwards et al. 2020; Luo et al. 2020). These results indicate that SADS-CoV already exhibits crossspecies transmissibility from bats to pigs with the potential to spread to other animals. Although SADS-CoV was not identified after February 2019, it's important to monitor SADS-CoV, bat HKU2 and similar CoVs for the prevention of disease outbreaks.

\section{Alphacoronavirus 1}

The subgenus Tegacovirus contains 1 viral species, Alphacoronavirus 1 . This viral species includes a variety of common pathogens that infect livestock or pets (pigs, dogs, cats, etc.), such as TGEV, PRCV, CCoV and FCoV. In 1946, TGEV was first detected in the United States and is now endemic worldwide (He et al. 2020a). TGEV is a porcine enteropathogenic pathogen infecting pigs of all ages that leads to severe diarrhea and villous atrophy, causing high mortality in piglets (Doyle and Hutchings 1946). PRCV, which causes respiratory syndromes, is a variant derived from TGEV with a deletion in $\mathrm{S}$ gene (Wang and Zhang 2017). CCoV is a worldwide gastroenteric pathogen causing mild enteritis in young dogs (Decaro et al. 2012). CCoV is divided into 2 subtypes, $\mathrm{CCoV}$ type I (CCoV-I) and type II (CCoV-II), based on genetic divergence in $\mathrm{S}$ gene (Pratelli et al. 2003). FCoV infects cats and is endemic in different regions around the world. Normally, FCoV infection is asymptomatic or causes mild enteric disease, but some cases (approximately $5 \%$ ) lead to feline infectious peritonitis (some mutant FCoVs are also known as feline infectious peritonitis virus, FIPV) (Lewis et al. 2015). CoVs of Alphacoronavirus 1, including TGEV, PRCV, $\mathrm{CCoV}$ and FCoV, are closely related. Homologous recombination occasionally occurs in these viruses, leading to the emergence of new strains. For instance, the CCoV-IIb subtype of CCoV-II is a recombinant form of CCoV-II and TGEV, and serotype 2 of FCoV was generated via the recombination of type $1 \mathrm{FCoV}$ and $\mathrm{CCoV}$ (Herrewegh et al. 1998; Decaro et al. 2009). CoVs high similar to Alphacoronavirus 1 have not been detected in wild animals, such as bats, and thus, the exact origin of these viruses is unclear.

\section{Other alpha-CoVs}

The subgenus Minacovirus has 1 species, mink coronavirus 1 (MCoV). $\mathrm{MCoV}$ causes epizootic catarrhal gastroenteritis (ECG) in mink with high morbidity (approximately $100 \%$ ) and low mortality $(<5 \%)$ and has affected mink industry in Europe, America and Asia (Gorham et al. 1990). ECG disease was first reported in 1975, and CoV-like particles were identified in ECG biopsies by electron microscopy in the 1990s; however, the genome of $\mathrm{MCoV}$ was not identified until the 2010s (Gorham et al. 1990; Vlasova et al. 2011). In 2011, Anastasia et al. reported the full-length genome sequences of 2 MCoVs (WD1127 from Wisconsin and WD1133 from Minnesota), sharing $91.7 \%$ nt identity between their genomes (Vlasova et al. 2011). WD1127 and WD1133 share high aa identity in ORF1a and ORF1b polyproteins ( $94.2 \%$ and $97.9 \%$, respectively) but only $86.3 \%$ aa identity in $\mathrm{S}$ proteins. In addition to $\mathrm{MCoV}, 2$ types of ferret coronavirus (FRCoV), ferret systemic coronavirus (FRSC $\mathrm{V})$ and ferret enteric coronavirus (FRECV), were reported (Wise et al. 2010). FRECV infection of ferrets does not cause high mortality rates, but FRSCV infection can lead to systemic pyogranulomatous inflammation and may be fatal (Wise et al. 2006). Overall, the aa identity between FRCoV and MCoV is approximately $90 \%$ in the conserved replicase domains, suggesting that FRCoV and $\mathrm{MCoV}$ may represent 2 different species based on the latest classification standard (Lamers et al. 2016; International Committee on Taxonomy of Viruses Executive 2020).

The subgenus Luchacovirus has 1 species, Lucheng Rn rat coronavirus (RatCoV LRNV). LRNV was detected in Rattus norvegicus samples collected in 2013 in China (Wang et al. 2015). Recently, additional CoVs have been identified in rats and voles, including the AcCoV-JC34 strain in Apodemus chevrieri, the RtMruf-CoV-1/JL2014 strain in Myodes rufocanus, the RtRl-CoV/FJ2015 strain in Rattus losea and the UKRn3 strain in Rattus norvegicus (Ge et al. 2017; Wu et al. 2018; Tsoleridis et al. 2019). These rodent CoVs share greater than $90 \%$ aa identity in the conserved replicase domains but had less than $70 \%$ aa identity in $\mathrm{S}$ proteins, which may reflect their adaptation in different hosts. Usually, all rodent CoVs are clustered together in phylogenetic trees based on different genes, which indicates a common ancestor of them (Tsoleridis et al. 2019). In addition, 3 other strains detected in Europe, L232 in Oryctolagus cuniculus (rabbit) in France, UKMa1 in Microtus agrestis (field vole) in the United Kingdom and PLMg1 in Myodes glareolus (bank vole) in Poland were phylogenetically 
clustered together with rodent alpha-CoVs in the ORF1b tree but showed a certain genetic distance from other rodent alpha-CoVs (Tsoleridis et al. 2019). Surprisingly, rodent alpha-CoVs cluster together with HKU2, including SADS-CoV and other related bat CoVs, in the beta$\mathrm{CoV}$ group based on the spike tree, which indicates an ancient recombination event between them (Pan et al. 2017; Tsoleridis et al. 2019). Rodentia is the largest mammalian order, harboring $\sim 2,200$ species. Rodents carry diverse pathogens and are an important source of emerging viral infections. Recently, an increasing number of CoVs have been isolated from rodents, and more are expected in the future. Since rodents and many kinds of animals share habitats, monitoring rodent CoVs could be beneficial for the prevention and control of CoVrelated diseases.

The subgenera Soracovirus and Sunacovirus each contain 1 viral species, Sorex araneus coronavirus T14 (Shrew-CoV/Tibet2014) and Suncus murinus coronavirus X74 (Xīngguō-74 or known as WESV), respectively. Shrew-CoV/Tibet2014 and Xīngguō-74 have been identified in different shrews, Sorex araneus and Suncus murinus, respectively, in China (Wang et al. 2017; Wu et al. 2018). Both of them belong to the Soricidae family and Soricomorpha order. In addition to Xīngguō-74, other strains were also identified in shrews in China, including Wénchéng shrew virus (WESV) and Yúdū shrew virus (Yúdū-76), which showed moderate genetic diversity (Wang et al. 2017). CoVs detected in shrews in China, which are represented by Shrew-CoV/ Tibet2014 and Xīngguō-74, are clustered together, forming a distinct group. However, shrew CoVs show distinct phylogenetic relationships to other known alpha-CoVs, indicating that these viruses are from different origins and have distinct evolutionary characteristics (Wang et al. 2017; Wu et al. 2018).

\section{Beta-CoVs}

The genus Betacoronavirus currently contains 5 subgenera (Embecovirus, Hibecovirus, Mergecovirus, Nobecovirus, and Sarbecovirus) and 14 species. Beta-CoV is well known because it includes the most pathogenic CoVs to human beings, such as SARS-CoV, MERS-CoV and SARS-CoV-2, as well as a large number of related bat CoVs ( Hu et al. 2015; Wong et al. 2019; Hu et al. 2021). The Beta-CoV species include Betacoronavirus 1, China rattus coronavirus HKU24, human coronavirus HKU1, murine coronavirus and Myodes coronavirus 2JL14 in subgenus Embecovirus, bat $\mathrm{Hp}$ betacoronavirus Zhejiang2013 in subgenus hibecovirus, hedgehog coronavirus 1, Middle East respiratory syndrome-related coronavirus, pipistrellus bat coronavirus HKU5 and tylonycteris bat coronavirus HKU4 in subgenus Merbecovirus. Eidolon bat coronavirus C704, Rousettus bat coronavirus GCCDC1and Rousettus bat coronavirus HKU9 in subgenus Nobecovirus, and severe acute respiratory syndrome-related coronavirus in subgenus Sarbecovirus.

\section{Human beta-CoVs}

HCoV-OC43 and HKU1 Five types of beta-CoVs classified into 4 representative species have been reported to infect humans: $\mathrm{HCoV}-\mathrm{OC} 43$ of Betacoronavirus 1, HCoV-HKU1, MERS-CoV of Middle East respiratory syndrome-related coronavirus (MERSr-CoV), SARS$\mathrm{CoV}$ and SARS-CoV-2 of severe acute respiratory syndrome-related coronavirus (SARSr-CoV) $(\mathrm{Hu}$ et al. 2021). OC43 and HKU1 were discovered in patients with respiratory diseases in 1967 and 2005, respectively (Hamre and Procknow 1966; Woo et al. 2005). OC43 and HKU1, together with the other 2 alphaCoVs, 299E and NL63, are associated with a wide range of respiratory outcomes, including bronchiolitis and pneumonia and cause nonrespiratory organ system diseases, such as enteric and nervous systems (Zeng et al. 2018). Although these CoVs are considered one of the most common respiratory pathogens associated with respiratory tract infections in children and elderly individuals, particularly severe infections in infants, clinical epidemiological investigations have revealed a higher positive rate of these CoVs in adults, ranging from 50 to 59 years old (Cabeça et al. 2013). In some seasons, OC43 could be the most frequent virus detected in acute respiratory tract infection cases and had a more frequently abnormal pulmonary rate than the other $3 \mathrm{CoVs}$ (Zeng et al. 2018).

OC43 has a global distribution, and circulating OC43 viruses have high genetic diversity with at least 5 distinct genotypes (A to E) (Kin et al. 2015). Recombination of different types promotes the generation of new viral types. For example, OC43-D emerged via recombination between genotypes $\mathrm{B}$ and $\mathrm{C}$, and OC43-E emerged via recombination among genotypes $\mathrm{B}, \mathrm{C}$, and $\mathrm{D}$ (Zhang et al. 2015). In viral classification, OC43 belongs to the species Betacoronavirus 1, together with various closely related CoVs detected in other animals (Fig. 3). In addition to OC43, the other related CoVs in species Betacoronavirus 1 include HKU23 detected in dromedary camels, bovine $\mathrm{CoV}(\mathrm{BCoV})$ in bovine and alpaca, $\mathrm{SACoV}$ in Sable antelope, $\mathrm{GiCoV}$ in giraffe, canine respiratory $\mathrm{CoV}(\mathrm{CRCoV})$ in dog, porcine hemagglutinating encephalomyelitis virus (PHEV) and equine $\mathrm{CoV}$ (ECoV) (Fig. 3) (Woo et al. 2014b). Phylogenetically, CoVs of betacoronavirus 1 are most closely related to another species, China Rattus coronavirus HKU24 
(HKU24), in the subgenus Embecovirus (Fig. 3). HKU24 and similar viruses have been found in rats, such as Rattus norvegicus, Apodemus agrarius, and Apodemus chevrieri (Lau et al. 2015; Wang et al. 2015; Ge et al. 2017). The RdRp and Hel proteins of OC43 and HKU24 exhibit $91.8 \%$ and $93.5 \%$ aa sequence identity, respectively (Lau et al. 2015). Current evidence indicates that OC43 likely originated from rodents and may be transmitted to humans via livestock, such as bovines (Wang et al. 2015; Forni et al. 2017; Ge et al. 2017).

HKU1 was first reported in 2005 in a 71-year-old patient with pneumonia and bronchiolitis in Hong Kong (Woo et al. 2005). Since then, HKU1 has been detected in France, USA, Brazil, Australia, etc., indicating its global distribution (Siu et al. 2014; Zeng et al. 2018). Strains of HKU1 are divided into 3 genotypes, A, B and C, based on their phylogenetic relationships (Woo et al. 2006b). Recombination between different genotypes may lead to the emergence of novel genotypes. For instance, the recombination of hemagglutinin esterase (HE) coding regions between $\mathrm{A}$ and $\mathrm{B}$ generated genotype C (Woo et al. 2006b; Dominguez et al. 2014). HKU1 is closest to murine coronavirus (known as mouse hepatitis virus, MHV) according to phylogenetic analysis, and different strains of murine coronavirus have been detected in rats (rat CoV Parker) and mice (MHV, Fig. 3) (Das Sarma et al. 2001). One hypothesis is that HKU1 originates from rodents, but its intermediate host is still unclear (Forni et al. 2017; Cui et al. 2019).

SARS-CoV and SARS-CoV-2 Severe acute respiratory syndrome coronavirus (SARS-CoV) and severe acute respiratory syndrome coronavirus 2 (SARS-CoV-2) are highly pathogenic human CoVs (Falsey and Walsh 2003; $\mathrm{Zhu}$ et al. 2020). SARS-CoV caused a relatively short epidemic of SARS in 2002-2003, resulting in more than 8,000 clinical cases with a mortality of $10 \%$ (Parry 2003; Stadler et al. 2003). However, ongoing SARS-CoV-2 has caused an extensive pandemic, termed coronavirus disease 2019 (COVID-19), beginning the end of 2019, leading to more than a hundred million cases and millions of deaths worldwide ( $\mathrm{Hu}$ et al. 2021). Both SARS-CoV and SARS-CoV-2 are primarily transmitted and enter through the respiratory tract, and the primary symptom is acute severe pneumonia (Huang et al. 2020a; Zhu et al. 2020). However, compared to SARS-CoV, SARSCoV-2 reportedly has a wider histotropic range of infection, including the intestinal tract, kidney, nervous system and so on (Chen et al. 2020a; Hu et al. 2021; Huang et al. 2020a). In addition, SARS-CoV-2 exhibits high transmissibility, with an R0 value estimated as 2.3 but that could be as high as 5.7, and a long incubation period of 5.4 median incubation days is estimated for SARS-CoV-2 infection, which can be as long as 13.7 days in $95 \%$ of symptomatic cases and even longer in some asymptomatic cases (Yang et al. 2020a). The COVID-19 pandemic has become a serious global public health problem that has challenged our knowledge of virology and systems of viral disease control.

The overall genomic sequence identity between SARS$\mathrm{CoV}$ and SARS-CoV-2 is 79.6\%; however, aa identities of ORF1a and ORF1b between them are $80.9 \%$ and $95.7 \%$, respectively (Zhou et al. 2020b). Based on the new demarcation criteria, they belong to the same species, $s e-$ vere acute respiratory syndrome-related coronavirus (SARSr-CoV) Coronaviridae Study Group of the International Committee on Taxonomy of Viruses 2020). In $\mathrm{CoV}$ taxonomy, SARS-CoV, SARS-CoV-2, most bat $\mathrm{CoVs}$ and a few CoVs detected in civets, pangolins and other animals are classified in the SARSr-CoV subgenus Sarbecovirus (Fig. 4) (Coronaviridae Study Group of the International Committee on Taxonomy of Viruses 2020). Since the appearance of SARS, investigations on the origin of SARS-CoV have led to the discovery of a large number of novel CoVs in various animals, particularly in bats, and greatly promoted the understanding of the existence and spread of $\mathrm{CoVs}$ in nature $(\mathrm{Hu}$ et al. 2015; Wong et al. 2019). In 2005, CoV strains highly homologous to SARS-CoV were identified in the Chinese horseshoe bat (Rhinolophus sp. ), including Rp3, HKU3, etc. (Li et al. 2005; Woo et al. 2005). SARS-CoV uses angiotensin-converting enzyme 2 (ACE2) as its receptor to enter cells (Li et al. 2003). In 2013, WIV1, a living bat CoV using the same ACE2 receptor as SARS-CoV, was isolated from a Rhinolophus sinicus sample ( $\mathrm{Li}$ et al. 2003; Ge et al. 2013). The overall nt identity of WIV1 genome with human SARS-CoV is $95.4 \%$. In 2015, another bat CoV strain, WIV16, which shows higher genomic sequence identity (96\% nt identities) to SARS-CoV, was isolated (Yang et al. 2015). A 5-year surveillance of bat SARSr-CoVs in Yunnan Province, China, revealed that the SARSr-CoVs circulating in bats are highly diverse and have high genetic similarity to SARS-CoV in the hypervariable N-terminal domain (NTD) and receptor-binding domain (RBD) of S1 gene, ORF3 and ORF8, respectively ( $\mathrm{Hu}$ et al. 2017). During the SARS epidemic, SARS-CoV was detected in some animal species, such as civets in southern China, which showed genomic nt identities of $99.8 \%$ to human SARS-CoV, indicating interspecies transmission of SARS-CoV between animals and humans (Guan et al. 2003).

Benefitting from previous SARS-CoV and SARSr-CoV research, within a short time after the outbreak of SARS-CoV-2, a bat CoV strain (RaTG13) showing high similarity to SARS-CoV-2 was identified (Zhou et al. 2020b). The overall nt identity of genomes between 
SARS-CoV-2 and RaTG13 is $96.2 \%$, and the aa identities of ORF1a, ORF1b, and S protein between SARS-CoV-2 and RaTG13 are 98\%, 99.3\%, and 97.7\%, respectively, suggesting that SARS-CoV-2 and RaTG13 are highly homologous (Zhou et al. 2020b). Although the aa identity of $\mathrm{S}$ proteins between SARS-CoV and SARS$\mathrm{CoV}-2$ is only approximately $77 \%$, SARS-CoV-2 also uses ACE2 as its entry receptor (Zhou et al. 2020b). Other $\mathrm{CoV}$ strains close to SARS-CoV-2 include bat SARSr-CoV ZC45, ZXC21 and RmYN02 (Fig. 4) (Hu et al. 2018; Zhou et al. 2020a, b), but their genomes exhibit lower homology to that of SARS-CoV-2 than RaTG13. It is worth noting that RaTG13, ZC45/ ZXC21 and RmYN02 were found in different Rhinolophus bat species: Rhinolophus affinis, Rhinolophus pusillus, and Rhinolophus malayanus, respectively. In addition to bats, $\mathrm{CoV}$ strains (pangolin-CoV) close to SARS-CoV-2 were also detected in pangolins (Lam et al. 2020; Xiao et al. 2020). Pangolins infected with pangolin-CoV showed clinical signs and histological changes, indicating that pangolins are probably not a natural reservoir but an intermediate host of SARSCoV-2 (Xiao et al. 2020). However, all SARSr-CoVs detected in bats (RaTG13, ZC45/ZXC21, and RmYN02) and pangolins (pangolin-CoV) are different from human SARS-CoV-2 in their genomic sequences and certain special genes. In particular, $S$ protein of SARS-CoV-2 harbors a unique furin cleavage site that is lacking in animal SARSr-CoVs, suggesting that SARSr-CoVs are not the origin of SARS-CoV-2 (Wang et al. 2020b). Due to the long-term pandemic of SARS-CoV-2, it has been detected in a wide variety of animals, including cats, tigers, minks and dogs, but they are likely to be transmitted from COVID-19 patients (Oude Munnink et al. 2021). Both SARS-CoV and SARS-CoV-2 exhibited broad ACE2 usage, indicating their wide range of hosts (Wang et al. 2020a).

In the phylogenetic tree based on $\mathrm{S}$ proteins, SARSr-CoV formed 3 clusters. Human and civet SARS-CoV strains are clustered with various bat SARSr-CoVs derived from Rhinolophus sinicus, Rhinolophus pusillus, Rhinolophus ferrumequinum, Rhinolophus macrotis, etc. However, the most homologous strains were all detected from Rhinolophus sinicus, such as WIV1, indicating the host specificity of these CoVs. The SARS-CoV-2 strains cluster with RaTG13, pangolin-CoV, ZC45/ZXC21 and RmYN02. Moreover, the other 2 bat SARSr-CoVs, JL2012 and Rf4092, cluster together. These results suggest that Rhinolophus bats are a natural reservoir of SARSr-CoVs and bat SARSr-CoVs occasionally spill over across species to infect humans or other animals. However, the exact timing of the spillover of SARSr-CoVs remains obscure.
MERS-CoV MERS-CoV is detected in both humans and dromedaries. Several closely related bat $\mathrm{CoVs}$ are classified into the species Middle East respiratory syndromerelated coronavirus in the subgenus Merbecovirus (Wong et al. 2019). Symptoms caused by MERS-CoV infection range from none to mild or severe respiratory ailments, including fever, cough, shortness of breath, and, on occasion, pneumonia and gastrointestinal symptoms (de Wit et al. 2016). Since the first report of MERS in Saudi Arabia in 2012, 2519 laboratory-confirmed cases of MERS-CoV have been reported, causing 866 deaths (34.3\% mortality) in 27 countries globally (Zaki et al. 2012; http://www.emro.who.int/pandemic-epidemicdiseases/mers-cov/mers-situation-update-january-2020. html). To date, MERS cases have been reported in 12 countries in the Middle East and are prevalent primarily in Saudi Arabia, where $80 \%$ of all MERS cases have been reported (Chafekar and Fielding 2018). MERS cases have also been reported in countries outside the Middle East, likely due to international travel (Fanoy et al. 2014). Unlike SARS-CoV and SARS-CoV-2, MERS-CoV exhibits limited human-to-human transmission and does not usually cause sustainable epidemics (Mailles et al. 2013). However, an explosive MERS epidemic was reported in Korea from 20 May to 13 June 2015, in which an imported MERS case led to 185 infections and 36 deaths (Korean Society of Infectious Diseases and Korean Society for Healthcare-associated Infection Control and Prevention 2015).

MERS-CoV is a zoonotic virus, and transmission of this virus from dromedaries to humans through direct or indirect contact with infected animals has been documented (The Health Protection Agency Uk Novel Coronavirus Investigation Team 2013; Memish et al. 2014). CoVs isolated from dromedaries showed $>99 \%$ genomic nt identity with human MERS-CoV, further demonstrating transmission of the virus between camels and humans (Chu et al. 2014; Haagmans et al. 2014). Nucleic acid detection, sequencing and phylogenetic evidence indicates that MERS-CoV exists in dromedaries in Africa and the Middle East, confirming that the virus is prevalent in dromedaries (Reusken et al. 2014; Sabir et al. 2016). In addition, serological evidence on MERS-CoV revealed that antibodies in dromedaries in Africa and the Middle East exhibit high neutralizing titers against MERS-CoV (Reusken et al. 2013; Ommeh et al. 2018). Antibodies against MERS-CoV in dromedaries were detected as early as the 1980s, indicating the long-term existence and infection of MERS-CoV or MERSr-CoV in dromedaries (Müller et al. 2014). As a result, the exact time in history when MERS-CoV spread between camels and humans and among humans remains uncertain.

In bats, a few strains of MERSr-CoV have been detected. In 2014, a bat CoV detected in the South African 
Neoromicia capensis bat (NeoCoV) was clustered as a basal sister clade of MERS-CoV. NeoCoV had 92.7\%, $96.4 \%, 98.6 \%$ and $98.5 \%$ aa sequence identities with ORF1ab polyprotein, 3CLpro, RdRp and Hel proteins of MERS-CoV, respectively (Corman et al. 2014a). In addition to NeoCoV, bat MERSr-CoVs were also discovered in Pipistrellus bats in Romania and Ukraine, Eptesicus bats in Italy, Nyctinomops bats in Mexico, Vespertilio superans bats in China (BtVs-BetaCoV/SC2013), Pipistrelle bats in China (HKU25), etc., and these bat MERSr-CoVs share more than $96 \%$ aa identity with MERS-CoV in the partial RdRp protein (Yang et al. 2014a; Hu et al. 2015; Lau et al. 2018b). Therefore, these bat CoVs and MERS-CoV originated form the MERSr$\mathrm{CoV}$ species. Nevertheless, bat MERSr-CoVs are unlikely to be the direct ancestor of MERS-CoV due to the extremely low similarity in some genes between bat MERSr-CoVs and MERS-CoV. For example, NeoCoV and MERS-CoV share $64.3-64.6 \%$ aa identity only in S proteins (Corman et al. 2014a). The transmission of MERSr-CoVs among bats, dromedaries and humans remains to be further revealed.

In the subgenus Merbecovirus, there are 3 other viral species, Hedgehog coronavirus 1 (HedCoV1), Tylonycteris bat coronavirus HKU4 (HKU4), and Pipistrellus bat coronavirus HKU5 (HKU5) (Lau et al. 2019a). After the emergence of MERS-CoV, HedCoV1 was identified in hedgehogs in Europe and China and named EriCoV and Ea-HedCoV HKU31 (HKU31), respectively (Corman et al. 2014b; Lau et al. 2019a). EriCoV and HKU31 are classified in HedCoV1 species, which is the species closest to MERSr-CoV according to their genomic similarity and phylogenetic relationship (Lau et al. 2019a). Before the emergence of MERS-CoV in 2007, HKU4 and HKU5 were detected in lesser bamboo bats (Tylonycteris pachypus) and Japanese pipistrelle bats (Pipistrellus abramus), respectively (Woo et al. 2007). HKU4 and HKU5 came form 2 independent sister species, which are close to the other two species, HedCoV1 and MERSr-CoV (Fig. 3) (Lau et al. 2018b). Evidence that bat CoVs, such as HKU4 and HKU25, use human dipeptidyl peptidase 4 (hDPP4), the MERS-CoV receptor, for cell entry suggests a bat origin for MERS-CoV (Yang et al. 2014b; Lu et al. 2015; Lau et al. 2021).

\section{Other bat beta-CoVs}

In addition to bat CoVs HKU4, HKU5, MERSr-CoV, and SARSr-CoV mentioned above, there are 4 other species of bat beta-CoVs, including bat Hp-betacoronavirus Zhejiang2013 (BtHp-BetaCoV/ZJ2013) in the subgenus Hibecovirus, Eidolon bat coronavirus C704 (CMR704), Rousettus bat coronavirus GCCDC1 (Ro-BatCoV GCCD C1), and Rousettus bat coronavirus HKU9 (HKU9) in the subgenus Nobecovirus. BtHp-betaCoV/ZJ2013 has been observed in Hipposideros pratti bats in China (Wu et al. 2016). BtHp-BetaCoV/ZJ2013 showed 78\% RdRp aa identity with beta-CoVs and represents a separate clade in the tree of beta-CoVs (Fig. 3). BtHp-betaCoV/ ZJ2013 also displays a unique genomic structure containing an ORF2 between ORF1ab and S gene (Fig. 5) (Wu et al. 2016). CMR704 was detected in Eidolon helvum bats in Cameroon (Yinda et al. 2018). Ro-BatCoV GCCDC1 was first identified in Rousettus leschenaulti bats in Yunnan, China in 2016. The most remarkable feature of the Ro-BatCoV GCCDC1 genome is a 3 '-end derived from reovirus, indicating a cross-family recombination event between $\mathrm{CoV}$ and reovirus (Huang et al. 2016). Similar recombination was also reported in a $\mathrm{CoV}$ detected in lesser dawn bats (Eonycteris spelaea) in Singapore (Paskey et al. 2020). HKU9 was first identified in Leschenault's rousette bats (Rousettus lechenaulti) in China and has been commonly observed in Rousettus bats (Woo et al. 2007). It is worth mentioning that BtHp-BetaCoV/ZJ2013, Ro-BatCoV GCCDC1, and HKU9 in the subgenus Nobecovirus all form a distinct branch in the tree and are detected in fruit bats only, indicating the host specificity of these viruses (Fig. 3).

\section{Rodent beta-CoVs}

All rodent beta-CoVs are classified in the subgenus Embecovirus. In addition to HKU24 and murine coronavirus (MHV) mentioned above, another rodent viral species, Myodes coronavirus 2JL14 (RtMruf-CoV-2/JL2014), is in the subgenus Embecovirus (Wu et al. 2018). 2JL14 was detected in gray-sided voles (Myodes rufocanus) in China in 2018 (Wu et al. 2018). Similar to other rodent beta-CoVs, it's also close to CoVs in the species Betacoronavirus 1 in the subgenus Embecovirus (Fig. 3).

\section{Gamma-CoVs}

The genus Gammacoronavirus consists of 3 subgenera: Igacovirus, Brangacovirus and Cegacovirus (Lefkowitz et al. 2018). Igacovirus subgenus contains 3 species: avian coronavirus, avian coronavirus 9203, and duck coronavirus 2714. Viruses of Igacovirus subgenus primarily infect birds, such as chickens (Gallus gallus), turkeys, ducks, geese, pheasants, partridges, pigeons and peafowl (Cavanagh et al. 2002; Jonassen et al. 2005; Cavanagh 2007; Sun et al. 2007; Domanska-Blicharz et al. 2020). Infectious bronchitis virus (IBV) is the prototype virus of Igacovirus subgenus, and various serotypes of IBV have been identified. IBV is the causal agent of infectious bronchitis that is prevalent worldwide and primarily infects the upper respiratory tract, but several IBV serotypes also infect kidney, digestive tract and reproductive system (Reddy et al. 2015; Hou et al. 2020). The genome of IBV contains at least 10 ORFs characterized by the following organization: 5'UTR-ORF1a/1b-S-3a-3b-E-M- 
$5 \mathrm{a}-5 \mathrm{~b}-\mathrm{N}-3$ 'UTR. High rates of mutation and recombination have been observed in IBV genome and are considered to be the key factor driving adaptive evolution and host shift in this virus (Hewson et al. 2011; Latinne et al. 2020; Marandino et al. 2017). Genomic mutations of IBV are primarily located in the coding region of $\mathrm{S}$ protein, among which some mutations are reported to reduce the virulence of IBV, and most adaptive marker mutations occur in S1 subunit (Cavanagh et al. 1988). Nevertheless, mutations of S2 subunit have been reported to alter the membrane fusion ability of viral particles, leading to potential infectivity in nonbird species, such as mammals (Fang et al. 2005). In addition to $\mathrm{S}$ protein, coding regions of ORF1ab, especially those of NSP2, NSP3 and NSP16, also harbor many hotspots for mutation and recombination (Thor et al. 2011). Similar to mutations, most recombination events of IBV genome also tend to reduce the virulence of IBV (Huang et al. 2020b).

Subgenus Brangacovirus contains only 1 species, goose coronavirus $C B 17$, which is named after the newly identified gammacoronavirus Canada goose coronavirus (CGCoV) that infects the goose species Branta canadensis (Papineau et al. 2019). Genome of CGCoV aligns with the following structure: 5'UTR-ORF1a/1b-S-ORF3-4a-EM-5b-ORF6-7a-7b-8a-8b-N-ORF10-ORF11-3'UTR. Similar to avian coronaviruses (ACoVs), several transcription regulatory sequences (TRSs) are located at the end of each leader sequence of $\mathrm{CGCoV}$, but the number of TRSs in $\mathrm{CGCoV}$ is twice as many as that of ACoVs (Papineau et al. 2019).

Subgenus Cegacovirus is represented by 2 viral strains, beluga whale coronavirus SW1 (BWCoV SW1) and bottlenose dolphin coronavirus HKU22 (BdCoV HKU22), which infect marine mammals (Mihindukulasuriya et al. 2008; Woo et al. 2014a). BWCoV SW1 belongs to the species of beluga whale coronavirus $S W 1$ characterized by the genomic structure 5'UTR-ORF1a/1b-S-E-M-5a-5b-5cORF6-ORF7-ORF8-ORF9-ORF10-N-3'UTR. Comparative genomic analyses demonstrated that BdCoV HKU22 harbors the same genomic structure as BWCOV SW1, particularly with respect to the putative TRSs, indicating that these 2 viruses can be classified into 1 species; however, this classification is still controversial since they share only $74.3-74.7 \%$ aa identity on their spike genes (Woo et al. 2014a). Currently, it is widely believed that BWCoV SW1 and BdCoV HKU22 both evolved from ACoVs (Woo et al. 2014a).

Gamma-CoVs do not express active NSP1, such as alpha-CoVs and beta-CoVs, to inhibit host protein production due to a lack of cleavage sites between NSP1 and NSP2. Alternatively, IBV expresses $5 \mathrm{~b}$ protein, performing similar functions to NSP1 of other coronaviruses (Kint et al. 2016). Among the subgenera of gamma-CoVs,
Brangacovirus and Cegacovirus lack the homologs of accessory proteins $3 \mathrm{a}$ and $3 \mathrm{~b}$, which are expressed by Igacovirus (Papineau et al. 2019), indicating high genomic similarity between Brangacovirus and Cegacovirus but not Igacovirus (Fig. 5). A recent study indicated that Brangacovirus is likely a transition stage in the evolution from Igacovirus to Cegacovirus (Papineau et al. 2019).

\section{Delta-CoVs}

There are 3 subgenera (Andecovirus, Buldecovirus, and Herdecovirus) in the genus Deltacoronavirus, harboring CoVs infecting mammals (Asiana leopard cat, Chinese ferret badger, and porcine) and birds (bulbul, thrush, munia, white eye, sparrow, magpie robin, night heron, wigeon, common moorhen, falcon, houbara, pigeon, and quail) (Dong et al. 2007; Woo et al. 2009; Woo et al. 2012; Lau et al. 2018a; Wang et al. 2021). Among mammalian delta-CoVs, porcine deltacoronavirus (PDCoV) has become one of the primary pathogens causing pig diarrhea since 2014 ( $\mathrm{Li}$ et al. 2014; Wang et al. 2014a). PDCoV was first discovered in a surveillance study in Hong Kong in 2012, and 2 strains with completed genomes were named HKU15-44 and HKU15-155 (Woo et al. 2012). Subsequently, PDCoVs were reported in other countries, including the United States, South Korea, Japan, mainland China, Thailand, Laos, Vietnam and other regions (Lee and Lee 2014; Li et al. 2014; Song et al. 2015; Janetanakit et al. 2016; Lorsirigool et al. 2016; Le et al. 2018; Suzuki et al. 2018).

PDCoV infects the digestive tracts of pigs, resulting in acute diffuse, severe atrophic enteritis with vomiting, watery diarrhea and severe dehydration with similar clinical symptoms to PED or TGE (Zhang 2016). The mortality of PDCoV-infected pigs ranges from 30 to $50 \%$ in piglets, which has seriously threatened pig breeding industry (Zhang 2016). Porcine aminopeptidase N (pAPN) has been demonstrated to be a functional receptor sufficiently mediating PDCoV entry (Wang et al. 2018). However, either knockout of pAPN or pAPN-specific antibody treatment cannot block the entry of PDCoV, indicating the existence of unknown redundant receptor(s) for PDCoV (Zhu et al. 2018). In addition, PDCoV may induce cellular autophagy (Qin et al. 2019).

The typical genomic organization of PDCoV is 5'UTRORF1a/1b-S-E-M-ORF6-N-7a/b/c-3'UTR, and the complete genome nucleotide identity of PDCoV strains in different regions ranges from $97.1 \%$ to $99.9 \%$, indicating a single genotype of PDCoV around the world (Zhang 2016). PDCoV can be divided into 4 genetic lineages: the United States-Japan-South Korea lineage, the Chinese lineage, the Thailand-Laos-Vietnam lineage and the early Chinese lineage (He et al. 2020b). Each lineage is relatively evolutionarily independent, while a recent study found that PDCoV strains SD2018/10 and 
AH2019/H in China originated from the United StatesJapan-South Korea lineage (He et al. 2020b).

Currently, there is still no direct evidence showing that $\mathrm{PDCoV}$ is transmitted by birds, and significant recombination events were only observed in porcine or bird deltacoronavirus (Lau et al. 2018a; Zhang et al. 2019; He et al. 2020b). However, it's generally believed that $\mathrm{PDCoV}$ and Asian leopard cat coronavirus (AlCCoV) evolved from bird coronavirus, and the closest evolutionary species to PDCoV among bird coronaviruses is the sparrow deltacoronavirus HKU17 (SpDCoV-HKU17) (Woo et al. 2012). It's worth noting that SpDCoVHKU17 in the United States shares approximately 83.9\% whole-genome nucleotide identity and greater than $85 \%$ aa identity for $\mathrm{S}$ protein with $\mathrm{PDCoV}$, which provides more evidence for the bird origin of PDCoV (Chen et al. 2018).

Recently, 3 Haitian children with acute undifferentiated febrile illness were tested positive for PDCoV (https://doi.org/10.1101/2021.03.19.21253391), which is the first report of delta-coronavirus infecting humans. Considering the close contact of people with pigs and other domestic animals, the potential of cross-species transmission of delta-coronaviruses to humans should not be neglected. We must be wary of the evolution of these virus in mammals to prevent related epidemics in the future.

\section{Genome structure of CoVs}

Genomic sizes of the known CoVs ranged from $24.5 \mathrm{~kb}$ to $31.8 \mathrm{~kb}$. Generally, genome size of CoVs in different genera varies; however, it tends to be similar in the same genus (Fig. 5). Genome length of beta-CoVs is similar, and the average size is approximately $30 \mathrm{~kb}$. Delta-CoVs have the shortest genome length, which is approximately $25 \mathrm{~kb}$. However, regardless genome size, genomic structure of $\mathrm{CoVs}$ is quite similar. genome organization follows the rule 5'-leader-UTR-replicase-S-E-M-N-3'-UTRpoly(A) tail, with accessory genes interspersed within genes and the 3' end of genome (Figs. 2 and 5) (Lu et al. 2020). The first two-thirds of genome encodes ORF1a and ORF1b polyproteins by ribosomal frame shifting mode, and polyproteins are cut into multiple proteins by a protease of virus itself, which contains unique protease activities (Posthuma et al. 2008). The cleaved proteins are nonstructural polyprotein 1-16 (nsp1-16), including RdRp, Hel, 3CLpro and other important domains that perform multiple functions in the process of genomic replication (Fig. 2a) (Nukoolkarn et al. 2008). Structural proteins of $\mathrm{S}, \mathrm{E}, \mathrm{M}$ and $\mathrm{N}$ are responsible for the formation of viral structures (Fig. 2b). In particular, S protein is a type of surface glycoprotein responsible for binding and recognizing host cell receptors, coordinating viral entry, and determining host tropism of virus to some extent (Gui et al. 2017). Other accessory genes with interspersed distribution, such as ORF3, ORF4, ORF5 and eta, are also redundant genes. However, evidence showed that these genes do have specific functions, such as regulating host immune response and potentially promoting virus replication ( $\mathrm{Li}$ et al. 2020b).

Although the overall structure of $\mathrm{CoV}$ genomes is relatively consistent, there are some detailed differences among different viruses. For example, bat $\mathrm{CoV}$ genome of BtHp-BetaCoV/ZJ2013 in subgenus Hibecovirus in genus Betacoroanvirus contains an ORF2 between ORF1ab and gene (Fig. 5) (Wu et al. 2016). CoVs in the subgenus Embecovirus in the genus Betacoroanvirus contain ORF2 and an HE between ORF1ab and S gene (Woo et al. 2005). At the same time, there are other subtle differences in the genome structure of CoVs in different genera. For example, alpha-CoVs and beta-CoVs usually have redundant genes between $\mathrm{S}$ and $\mathrm{E}$, such as ORF3 and ORF4, while the genomes of delta-CoVs do not have these redundant genes between $\mathrm{S}$ and $\mathrm{E}$, making their genomes more compact (Brian and Baric 2005; Chen et al. 2020b). In addition, the number of redundant proteins encoded by different CoVs varies greatly (Fig. 5) (Brian and Baric 2005).

\section{Other suborders of Nidovirales order}

In addition to the suborder Cornidovirineae, the Nidovirales order contains 7 more suborders: $A b-, A r-, M e s-$, Mo-, Na-, Ro- and Tor-nidovirineae (Walker et al. 2019). Members of these suborders and their hosts will be briefly introduced here.

\section{Suborder Abnidovirineae}

Currently, there is only 1 species, Aplysia abyssovirus 1, in the subgenus Aplyccavirus, genus Alphaabyssovirus, subfamily Tiamatvirinae, family Abyssoviridae, in the Abnidovirineae suborder (Fig. 1, Table 3). In 2018, by transcriptome studies, a nidovirus-like sequence assembly was detected in the marine gastropod Aplysia californica (California sea hare) and was named Aplysia abyssovirus (AAbV), which is the only member of the Abnidovirineae suborder (Bukhari et al. 2018). The genomic length of AAbV (likely the complete genome) is $35.9 \mathrm{~kb}$.

\section{Suborder Arnidovirineae}

The suborder Arnidovirineae contains 4 families, Arteriviridae, Gresnaviridae, Olifoviridae and Cremegaviridae. Viruses in this suborder have the smallest genomes, about 12-16 kb, compared to viruses in other suborders (van Marle et al. 1999). The Arteriviridae family is divided into 6 subfamilies and contains many important pathogenic viruses (Figs. 1 and 6, and Table 2). The host range of viruses in Artiviridae is extensive, including 


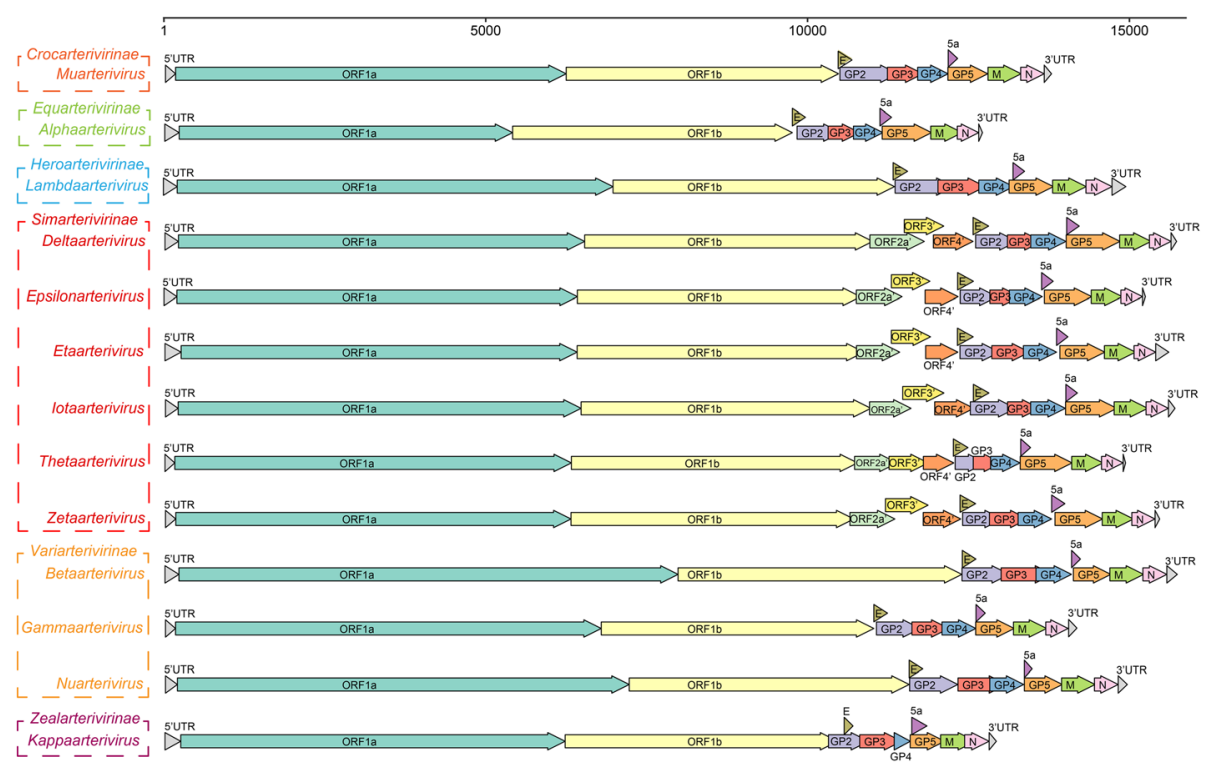

Fig. 6 Gene composition of viruses in 13 viral genera in Arteriviridae. The reference strains used for mapping in each genus are as follows: Muarterivirus (Olivier's shrew virus 1, NC_035127.1), Alphaarterivirus (Equine arteritis virus, NC_002532.2), Lambdaarterivirus (Forest pouched giant rat arterivirus, NC_026439.1), Deltaarterivirus (Simian hemorrhagic fever virus, NC_003092.2), Epsilonarterivirus (Free State vervet virus, NC_029992.1), Etaarterivirus (Kibale red colobus virus 2, NC_034455.1), lotaarterivirus (DeBrazzas monkey arterivirus, NC_026509.1), Thetaarterivirus (Kafue kinda chacma baboon virus, NC_029053.1), Zetaarterivirus (Kibale red colobus virus 1, NC_033553.1), Betaarterivirus (Rat arterivirus 1, NC_028963.1), Gammaarterivirus (Lactate dehydrogenase-elevating virus, NC_001639.1), Nuarterivirus (Rodent arterivirus, KY369969.1), Kappaarterivirus (Wobbly possum disease virus, NC_026811.2)

mammals and reptiles (Vanmechelen et al. 2018). Most infect mammals, including horses, donkeys, rats, monkeys, baboons, pigs, etc., and others infect reptiles, such as snakes and turtles (Lyu et al. 2019). Equine arteritis virus (EAV) (Zhang et al. 2008), porcine reproductive and respiratory syndrome virus (PRRSV) (Balasuriya and Carossino 2017), and simian hemorrhagic fever virus (SHFV) (Zeng et al. 1995; Bailey et al. 2016a) cause diseases in animals and are important pathogens in the Artiviridae family. Recently, some novel artiviruses, such as Trionyx sinensis hemorrhagic syndrome virus (TSHS V), infecting Pelodiscus sinensis (Chinese soft-shell turtle), have been identified (Lyu et al. 2020). Hosts of Gresnaviridae, Olifoviridae, and Cremegaviridae families are all reptiles. Each family has only 1 viral species, Ptyasnivirus 1, Oligodon snake nidovirus 1, and Chinturpovirus 1, whose hosts are Cyclophiops major, Oligodon formosanus, and Mauremys megalocephala, respectively (Table 2) (Shi et al. 2018). Diverse viruses in the Simarterivirinae subfamily have been identified, and all of them infect nonhuman primates, such as monkeys and baboons (Fig. 6, Table 2) (Lauck et al. 2013; Bailey et al. 2014; Lauck et al. 2015; Bailey et al. 2016a). At present, no similar viruses have been detected in humans. However, humans, monkeys and baboons are primates, and it's necessary to strengthen the monitoring of artiviruses to prevent cross-species transmission of these viruses to humans (Bailey et al. 2016b).

\section{Suborder Mesnidovirineae}

The suborder Mesnidovirineae contains Medioniviridae and Mesoniviridae families. Medioniviridae consists of Medionivinae and Tunicanivirinae subfamilies with marine invertebrate hosts. Medionivinae has one species, Turrinivirus 1, detected in Turritella sea snails, and Tunicanivirinae has 1 species, Botrylloides leachii nidovirus, detected in Botrylloides leachii (Shi et al. 2018). Comparatively, Mesoniviridae contains 10 viral species, which primarily infect mosquitoes, such as Culex, Aedes and uranotaenia, but some of them have also been detected in rats (Fig. 1, Table 3) (Zirkel et al. 2011; Lauber et al. 2012; Diagne et al. 2017). Aedes and Culex mosquitoes are important hosts of arboviruses (da Silva Ferreira et al. 2020). For example, yellow fever virus and dengue virus are mainly transmitted by Aedes. Culex can transmit Japanese encephalitis virus and other viruses. More attention should be paid to some viral strains of the Namcalivirus subgenus in the Alphameaonivirus genus, such as Hexponivirinae subfamily, and Mesoniviridae family, which can be transmitted between mosquitoes and mammals (Table 3) (Vasilakis et al. 2014). 


\section{Suborder Monidovirineae}

The suborder Monidovirineae has 1 viral species, Planidovirus 1, in the Dumedivirus subgenus, Alphamononivirus genus, Mononivirinae subfamily, and Mononiviridae family. Planidovirus 1 has only 1 viral strain named planarian secretory cell nidovirus (PSCN $\mathrm{V})$, which was detected in the transcriptome sequences of Schmidtea mediterranea (freshwater planarian) (Table 3). The detected genome of PSCNV reaches $41.1 \mathrm{~kb}$ in length, which is the largest RNA genome characterized so far (Saberi et al. 2018).

\section{Suborder Nanidovirineae}

The suborder Nanidovirineae is divided into 2 viral families, Nanghoshaviridae and Nanhypoviridae. To date, nanidoviruses have only been found in 2 types of fish. There is only 1 virus in each family, Nangarvirus 1 (13.2 kb genome) in Nanghoshaviridae detected in Chimaera sp., and Halfbeak nidovirus 1 (18.2 kb genome) in Nanhypoviridae found in Hyporhamphus sajori (Japanese halfbeak) (Table 3) (Shi et al. 2016; Shi et al. 2018).

\section{Suborder Ronidovirineae}

The suborder Ronidovirineae contains 2 viral families, Euroniviridae and Roniviridae. Ronidovirineae, named "rod-shaped nidovirus", is 150-200 nm long and approximately $60 \mathrm{~nm}$ thick (Boonyaratpalin et al. 1993). There are 3 viral species in the Tipravirus subgenus, Okavirus genus, and Okanivirinae subfamily in the Roniviridae family. Gill-associated virus (GAV), yellow head virus (YHV), and Okavirus 1 share a close genomic size of approximately $26 \mathrm{~kb}$ and infect different shrimp species, including Penaeus monodon (black tiger shrimp), Penaeus chinensis, and Penaeus semisulcatus (Cowley et al. 2004; Ma et al. 2009; Dong et al. 2017). Due to extensive aquaculture and the exchange of aquatic products, these viruses have been detected in many areas of the world with a variety of viral types, some of which are important aquatic pathogens (Soowannayan et al. 2013). There are 3 viral species in the Euroniviridae family, all of which have been detected in crustaceans (Shi et al. 2016).

\section{Suborder Tornidovirineae}

The suborder Tornidovirineae has a wide range of hosts, including fish, reptiles and mammals (Table 3). The Tornidovirineae suborder contains 1 viral family, Tobanivirdae, which has been divided into 4 subfamilies (Walker et al. 2019). Among them, viruses of the Piscanivirinae subfamily infect fish, such as white mullet and crucian carp (Schütze et al. 2006; Batts et al. 2012), viruses of the Remotovirinae subfamily infect cattle (Tokarz et al. 2015), viruses of the Serpentovirinae subfamily infect snakes and lizards (Stenglein et al. 2014; O'Dea et al.
2016; Shi et al. 2016), and viruses of the Torovirinae subfamily infect diverse mammals (including porcine, sheep, goat, horses, cattle and Tasmanian devil) and reptiles (snakes and turtles) (Pignatelli et al. 2010; Sun et al. 2014; Shi et al. 2018; Stewart et al. 2018; Chong et al. 2019; Li et al. 2020a). The subfamily Torovirinae was once classified into the family Coronaviridae, and the prototype species of torovirus is equine torovirus (EToV), which was identified in the 1970s (Lauber et al. 2012). In the 1980s, porcine torovirus (PToV) and bovine torovirus $(\mathrm{BToV})$ were detected (Pignatelli et al. 2010). Subsequently, torovirus was found in a large range of domestic ungulates, such as cattle, goats, sheep, pigs and horses, with worldwide distribution, causing acute self-limiting gastroenteritis and a significant burden to the animal industry (Hoet and Saif 2004). Currently, there are 3 species $\mathrm{BToV}$, EToV and PToV in the subgenus Renitovirus of genus Torovirus in the subfamily Torovirinae (King et al. 2018). The recently identified toroviruses in snakes and turtles have not yet been classified (Shi et al. 2018).

\section{Conclusions and perspectives}

In this century, knowledge about the universality, diversity, genetic evolution and host range of viruses has greatly expanded (Ge et al. 2012; Shi et al. 2016; Shi et al. 2018). Together with other knowledge regarding viruses, these findings have led to new standards and definitions of viral classification, and thus, the virus classification system recommended by ICTV is frequently being upgraded. In 2020, ICTV expanded the virus classification system from the old 5-rank hierarchy structure (from order to species) to the new 15-rank hierarchy structure (from realm to species) (International Committee on Taxonomy of Viruses Executive 2020). Viruses classified into the order Nidovirales synthesize 3CLpro, NiRAN, RdRp, ZBD and HEL1 proteins. Classification of nidovirus was also replaced by the new standard, and the latest classification of nidoviruses is based on sequence similarity of 5 genes, 3CLpro, NiRAN, RdRp, ZBD and HEL1 domains of the replicase protein, replacing the 7 previous domains of ADRP, 3CLpro, RdRp, NSP13, NSP14, NSP15 and NSP16. The lower ranks, including suborder, family, subfamily, genus, subgenus and species, are classified according to the overall identity of the concatenated domains of 3Clpro-NiRAN-RdRpZBD-HEL1. Thresholds of the demarcation criteria for each level are $73.4 \%, 68.3 \%, 51.9 \%, 36 \%, 14.7 \%$ and $7.6 \%$, respectively (International Committee on Taxonomy of Viruses Executive 2020).

At present, the order Nidovirales consists of 8 suborders including 109 species, which have a wide range of hosts from invertebrates (crustaceans and arthropods) to vertebrates (fishes, reptiles, amphibians, birds and mammals) 
(Saberi et al. 2018). Viral genome size and structure vary greatly among different suborders in the order Nidovirales. For example, genome of viruses in the suborder Arnidovirineae is usually less than $17 \mathrm{~kb}$, while that of viruses in the suborder Monidovirineae is $41 \mathrm{~kb}$, which is the largest RNA viral genome characterized at present (van Marle et al. 1999; Saberi et al. 2018). Viruses of the subfamily Simarterivirinae in the suborder Arnidovirineae have 3 additional genes, ORF2a', ORF3' and ORF4', compared to viruses in other subfamilies in suborder Arnidovirineae (Lauck et al. 2013). Notably, viruses in subfamily Simarterivirinae infect primates, and the additional genes may function to promote viral adaption to primate hosts (Bailey et al. 2014). The abundant virus types, wide host range, consistency and variation of genome and its coding components of nidoviruses may provide information about the evolutionary path, mutation mode, host adaptation and coevolution of these viruses, which provides excellent research materials for virus tracing and other virological studies. In this review, only viruses with a clear taxonomic status proposed by ICTV were listed and introduced, while many viral strains with sequences but without a clear taxonomic status were not referenced to avoid potential ambiguity. In the future, identification and classification of additional related viruses will help to better understand the origin and evolution of nidoviruses.

$\mathrm{CoVs}$ can be hosted in 45 species and are a large group in the order Nidovirales, which contains many pathogens that infect humans, poultry and livestock, posing great threats to public health and livestock farming (Jackwood et al. 2012; Graham et al. 2013; Cui et al. 2019). Previous studies on CoVs, especially in bats, rodents, poultry and livestock, have revealed relative host specificity of CoVs. For example, SARSr-CoV primarily exists in Rhinolophus bats, and in particular, the most relevant bat SARSr-CoV with human SARS-CoV virus only exists in Rhinolophus sinicus, while the most relevant virus to SARS-CoV-2 was detected in Rhinolophus affinis (Ge 2013; Zhou et al. 2020b). However, CoV has its own characteristics of rapid genetic variation due to the lack of sufficient correction in genomic RNA replication and frequent genome recombination, leading to diversity among CoVs (Brian and Baric 2005). In natural reservoirs, such as bats, rodents and birds, CoVs are endemic and show high genetic diversity (Wang et al. 2015; Wu et al. 2016; Ge et al. 2017; Tsoleridis et al. 2019). However, their rapid evolution and habitat crossover among animals lead to continuous and accidental cross-species transmission (Hu et al. 2015).

Research on SARS-CoV, SARS-CoV-2, and MERS$\mathrm{CoV}$ has revealed a wide range of potential hosts for these viruses (Barlan et al. 2014; Wang et al. 2020a). For instance, SARS-CoV-2 can infect and cause diseases in humans, dogs, cats, ferrets and other animals (Oude
Munnink et al. 2021). It has also been reported that human contact with other animals caused by long-term viral epidemics can lead to spread of the virus among different species, and sharing habitats is crucial for breaking interspecies barriers and the subsequent interspecific transmission of viruses (Oude Munnink et al. 2021). Because of the high diversity of CoVs carried by bats, rodents, and other animals and the widespread use of their host animals, monitoring natural CoVs and keeping a distance from wild animals are critical to prevent the transmission of $\mathrm{CoVs}$ to human habitats ( $\mathrm{Li}$ et al. 2020c).

The outbreak of several CoV pandemics in this century reminds us of the great threat of epidemic CoVs. The long-term prevalence of SARS-CoV-2 is partially due to the lack of attention to viral diseases and insufficient knowledge regarding pathogenic viruses. Therefore, it's important to popularize knowledge of virology, especially about viral diseases, in the public. Moreover, new preventive techniques and therapies developed according to the characteristics of viral pathogens will greatly contribute to the control of infectious diseases.

\section{Acknowledgments \\ This work was jointly funded by the National Natural Science Foundation of China (No. 32041001, 81902070, U2002218) and the Provincial Natural Science Foundation of Hunan Province (No. 2019JJ20004 and 2019JJ50035).}

\section{Authors' contributions}

All authors have read and approved the final version of the manuscript.

\section{Declarations}

Competing interests

The authors declare that they have no competing interests.

Received: 27 January 2021 Accepted: 4 March 2021

Published online: 23 April 2021

\footnotetext{
References

Azhar, E.I., S.A. El-Kafrawy, S.A. Farraj, A.M. Hassan, M.S. Al-Saeed, A.M. Hashem, and T.A. Madani. 2014. Evidence for camel-to-human transmission of MERS coronavirus. The New England Journal of Medicine 370 (26): 2499-2505. https://doi.org/10.1056/NEJMoa1401505.

Bailey, A.L., M. Lauck, R.R. Ghai, C.W. Nelson, K. Heimbruch, A.L. Hughes, T.L. Goldberg, J.H. Kuhn, A.J. Jasinska, N.B. Freimer, et al. 2016a. Arteriviruses, pegiviruses, and lentiviruses are common among wild African monkeys. Journal of Virology 90 (15): 6724-6737. https://doi.org/10.1128/jvi.00573-16.

Bailey, A.L., M. Lauck, S.D. Sibley, T.C. Friedrich, J.H. Kuhn, N.B. Freimer, A.J. Jasinska, J.E. Phillips-Conroy, C.J. Jolly, P.A. Marx, et al. 2016b. Zoonotic potential of Simian arteriviruses. Journal of Virology 90 (2): 630-635. https:// doi.org/10.1128/JVI.01433-15.

Bailey, A.L., M. Lauck, A. Weiler, S.D. Sibley, J.M. Dinis, Z. Bergman, C.W. Nelson, M. Correll, M. Gleicher, D. Hyeroba, et al. 2014. High genetic diversity and adaptive potential of two simian hemorrhagic fever viruses in a wild primate population. PLoS One 9 (3): e90714. https://doi.org/10.1371/journal.pone. 0090714.

Balasuriya, U.B., and M. Carossino. 2017. Reproductive effects of arteriviruses: equine arteritis virus and porcine reproductive and respiratory syndrome virus infections. Current Opinion in Virology 27: 57-70. https://doi.org/10.1016/ j.coviro.2017.11.005

Barlan, A., J.C. Zhao, M.K. Sarkar, K. Li, P.B. McCray, S. Perlman, and T. Gallagher. 2014. Receptor variation and susceptibility to Middle East respiratory
} 
syndrome coronavirus infection. Journal of Virology 88 (9): 4953-4961. https:// doi.org/10.1128/JVI.00161-14.

Batts, W.N., A.E. Goodwin, and J.R. Winton. 2012. Genetic analysis of a novel nidovirus from fathead minnows. The Journal of General Virology 93 (6): 1247-1252. https://doi.org/10.1099/vir.0.041210-0.

Boonyaratpalin, S., K. Supamattaya, J. Kasornchandra, S. Direkbusaracom, U. Aekpanithanpong, and C. Chantanachooklin. 1993. Non-occluded baculo-like virus, the causative agent of yellow head disease in the black tiger shrimp (Penaeus monodon). Fish Pathology. 28 (3): 103-109. https://doi.org/10.3147/ jsfp.28.103.

Brian, D.A., and R.S. Baric. 2005. Coronavirus genome structure and replication. Current Topics in Microbiology and Immunology 287: 1-30. https://doi.org/10.1 007/3-540-26765-4_1.

Brown, P.A., F. Touzain, F.X. Briand, A.M. Gouilh, C. Courtillon, C. Allée, E. Lemaitre, C. De Boisséson, Y. Blanchard, and N. Eterradossi. 2016. First complete genome sequence of European Turkey coronavirus suggests complex recombination history related with US Turkey and Guinea fowl coronaviruses. The Journal of General Virology 97 (1): 110-120. https://doi.org/10.1099/jgv.0. 000338.

Bukhari, K., G. Mulley, A.A. Gulyaeva, L.Y. Zhao, G.C. Shu, J.P. Jiang, and B.W. Neuman. 2018. Description and initial characterization of metatranscriptomic nidovirus-like genomes from the proposed new family Abyssoviridae, and from a sister group to the Coronavirinae, the proposed genus Alphaletovirus. Virology 524: 160-171. https://doi.org/10.1016/j.virol.2018.08.010.

Cabeça, T.K., C. Granato, and N. Bellei. 2013. Epidemiological and clinical features of human coronavirus infections among different subsets of patients. Influenza and Other Respiratory Viruses 7 (6): 1040-1047. https://doi.org/1 0.1111 irv.12101.

Castells, M., M. Victoria, R. Colina, H. Musto, and J. Cristina. 2017. Genome-wide analysis of Codon usage bias in Bovine Coronavirus. Virology Journal 14 (1): 115. https://doi.org/10.1186/s12985-017-0780-y.

Cavanagh, D. 2007. Coronavirus avian infectious bronchitis virus. Veterinary Research 38 (2): 281-297. https://doi.org/10.1051/vetres:2006055.

Cavanagh, D., P.J. Davis, and A.P.A. Mockett. 1988. Amino acids within hypervariable region 1 of avian coronavirus IBV (Massachusetts serotype) spike glycoprotein are associated with neutralization epitopes. Virus Research 11 (2): 141-150. https://doi.org/10.1016/0168-1702(88)90039-1.

Cavanagh, D., K. Mawditt, D.D.B. Welchman, P. Britton, and R.E. Gough. 2002. Coronaviruses from pheasants (Phasianus colchicus) are genetically closely related to coronaviruses of domestic fowl (infectious bronchitis virus) and turkeys. Avian Pathology 31 (1): 81-93. https://doi.org/10.1080/030794501201 06651.

Chafekar, A., and B.C. Fielding. 2018. MERS-CoV: understanding the latest human coronavirus threat. Viruses 10 (2):93. https://www.mdpi.com/1999-4915/10/2/ 93/htm.

Chen, F.Z., T.P. Knutson, S. Rossow, L.J. Saif, and D.G. Marthaler. 2019. Decline of transmissible gastroenteritis virus and its complex evolutionary relationship with porcine respiratory coronavirus in the United States. Scientific Reports 9 3953. https://doi.org/10.1038/s41598-019-40564-z.

Chen, J.F., X.Z. Liu, D. Shi, H.Y. Shi, X. Zhang, C.L. Li, Y.B. Chi, and L. Feng. 2013. Detection and molecular diversity of spike gene of porcine epidemic diarrhea virus in China. Viruses 5 (10): 2601-2613. https://doi.org/10.3390/v51 02601.

Chen, N.S., M. Zhou, X. Dong, J.M. Qu, F.Y. Gong, Y. Han, Y. Qiu, J.L. Wang, Y. Liu, Y. Wei, et al. 2020a. Epidemiological and clinical characteristics of 99 cases of 2019 novel coronavirus pneumonia in Wuhan, China: a descriptive study. Lancet 395 (10223): 507-513. https://doi.org/10.1016/S0140-6736(20)30211-7.

Chen, Q., L.Y. Wang, C.H. Yang, Y. Zheng, P.C. Gauger, T. Anderson, K.M. Harmon, J.Q. Zhang, K.J. Yoon, R.G. Main, et al. 2018. The emergence of novel sparrow deltacoronaviruses in the United States more closely related to porcine deltacoronaviruses than sparrow Deltacoronavirus HKU17. Emerging Microbes \& Infections 7 (1): 1-4. https://doi.org/10.1038/s41426-018-0108-Z.

Chen, Y., Q.Y. Liu, and D.Y. Guo. 2020b. Emerging coronaviruses: genome structure, replication, and pathogenesis. Journal of Medical Virology 92 (4): 418-423. https://doi.org/10.1002/jmv.25681.

Chong, R., M. Shi, C.E. Grueber, E.C. Holmes, C.J. Hogg, K. Belov, and V.R. Barrs. 2019. Fecal viral diversity of captive and wild Tasmanian Devils characterized using virion-enriched metagenomics and metatranscriptomics. Journal of Virology 93 (11): e00205-e00219. https://doi.org/10.1128/jvi.00205-19.

Chu, D.K.W., J.S.M. Peiris, H. Chen, Y. Guan, and L.L.M. Poon. 2008. Genomic characterizations of bat coronaviruses $\left(1 \mathrm{~A}, 1 \mathrm{~B}\right.$ and $\left.\mathrm{HKU}_{8}\right)$ and evidence for co-infections in Miniopterus bats. The Journal of General Virology 89 (5): 12821287. https://doi.org/10.1099/vir.0.83605-0.

Chu, D.K.W., L.L.M. Poon, M.M. Gomaa, M.M. Shehata, R.A.P.M. Perera, D. Abu Zeid, A.S. El Rifay, L.Y. Siu, Y. Guan, R.J. Webby, et al. 2014. MERS coronaviruses in dromedary camels, Egypt. Emerging Infectious Diseases 20 (6): 1049-1053. https://doi.org/10.3201/eid2006.140299.

Corman, V.M., I. Eckerle, Z.A. Memish, A.M. Liljander, R. Dijkman, H. Jonsdottir, K.J. Z. Juma Ngeiywa, E. Kamau, M. Younan, M. Al Masri, et al. 2016. Link of a ubiquitous human coronavirus to dromedary camels. Proceedings of the National Academy of Sciences USA 113 (35): 9864-9869. https://doi.org/10.1 073/pnas.1604472113.

Corman, V.M., N.L. Ithete, L.R. Richards, M.C. Schoeman, W. Preiser, C. Drosten, and J.F. Drexler. 2014a. Rooting the phylogenetic tree of middle East respiratory syndrome coronavirus by characterization of a conspecific virus from an African bat. Journal of Virology 88 (19): 11297-11303. https://doi.org/10.1128/ JVI.01498-14.

Corman, V.M., R. Kallies, H. Philipps, G. Gopner, M.A. Muller, I. Eckerle, S. Brunink, C. Drosten, and J.F. Drexler. 2014b. Characterization of a novel Betacoronavirus related to middle east respiratory syndrome coronavirus in European hedgehogs. Journal of Virology 88 (1): 717-724. https://doi.org/10.1128/jvi.01 600-13.

Coronaviridae Study Group of the International International Committee on Taxonomy of Viruses Executive on Taxonomy of Viruses. 2020. The species severe acute respiratory syndrome-related coronavirus: classifying 2019-nCoV and Naming it SARS-CoV-2. Nature Microbiology 5 (4): 536-544. https://doi. org/10.1038/s41564-020-0695-Z.

Cowley, J.A., L.C. Cadogan, C. Wongteerasupaya, R.A.J. Hodgson, V. Boonsaeng, and P.J. Walker. 2004. Multiplex RT-nested PCR differentiation of gillassociated virus (Australia) from yellow head virus (Thailand) of Penaeus monodon. Journal of Virological Methods 117 (1): 49-59. https://doi.org/10.101 6/j.jviromet.2003.11.018.

Crossley, B.M., R.E. Mock, S.A. Callison, and S.K. Hietala. 2012. Identification and characterization of a novel alpaca respiratory coronavirus most closely related to the human coronavirus 229E. Viruses 4 (12): 3689-3700. https://doi. org/10.3390/v4123689.

Cui, J., F. Li, and Z.L. Shi. 2019. Origin and evolution of pathogenic coronaviruses. Nature Reviews. Microbiology 17 (3): 181-192. https://doi.org/10.1038/s41579018-0118-9.

da Silva Ferreira, R., L.C. de Toni Aquino da Cruz, V.J. de Souza, N.A. da Silva Neves, V.C. de Souza, L.C.F. Filho, P. da Silva Lemos, C.P.S. de Lima, F.G. Naveca, M. Atanaka, et al. 2020. Insect-specific viruses and arboviruses in adult male culicids from Midwestern Brazil. Infection, Genetics and Evolution 85: 104561. https://doi.org/10.1016/j.meegid.2020.104561.

Das Sarma, J., L. Fu, S.T. Hingley, M.M.C. Lai, and E. Lavi. 2001. Sequence analysis of the $\mathrm{S}$ gene of recombinant MHV-2/A59 coronaviruses reveals three candidate mutations associated with demyelination and hepatitis. Journal of Neurovirology 7 (5): 432-436. https://doi.org/10.1080/135502801753170282.

De Sabato, L., D. de Lelli, F. Faccin, S. Canziani, I. Di Bartolo, G. Vaccari, and A. Moreno. 2019. Full genome characterization of two novel Alpha-coronavirus species from Italian bats. Virus Research 260: 60-66. https://doi.org/10.1016/j. virusres.2018.11.007.

de Wit, E., N. van Doremalen, D. Falzarano, and V.J. Munster. 2016. SARS and MERS: recent insights into emerging coronaviruses. Nature Reviews. Microbiology 14 (8): 523-534. https://doi.org/10.1038/nrmicro.2016.81.

Decaro, N., V. Mari, M. Campolo, A. Lorusso, M. Camero, G. Elia, V. Martella, P. Cordioli, L. Enjuanes, and C. Buonavoglia. 2009. Recombinant canine coronaviruses related to transmissible gastroenteritis virus of Swine are circulating in dogs. Journal of Virology 83 (3): 1532-1537. https://doi.org/1 0.1128/JVI.01937-08.

Decaro, N., V. Mari, G. Elia, D.D. Addie, M. Camero, M.S. Lucente, V. Martella, and C Buonavoglia. 2010. Recombinant canine coronaviruses in dogs, Europe. Emerging Infectious Diseases 16 (1): 41-47. https://doi.org/10.3201/eid1601. 090726.

Decaro, N., V. Mari, M. von Reitzenstein, M.S. Lucente, F. Cirone, G. Elia, V. Martella, V.L. King, A. Di Bello, K. Varello, et al. 2012. A pantropic canine coronavirus genetically related to the prototype isolate CB/05. Veterinary Microbiology 159 (1/2): 239-244. https://doi.org/10.1016/j.vetmic.2012.03.039.

Diagne, M.M., M. Faye, O. Faye, A. Sow, F. Balique, M. Sembène, L. Granjon, P. Handschumacher, O. Faye, M. Diallo, et al. 2017. Emergence of Wesselsbron virus among black rat and humans in Eastern Senegal in 2013. One Health 3: 23-28. https://doi.org/10.1016/j.onehlt.2017.02.001. 
Domanska-Blicharz, K., A. Lisowska, and J. Sajewicz-Krukowska. 2020. Molecular epidemiology of infectious bronchitis virus in Poland from 1980 to 2017. Infection, Genetics and Evolution 80: 104177. https://doi.org/10.1016/j. meegid.2020.104177.

Dominguez, S.R., S. Shrivastava, A. Berglund, Z.H. Qian, L.G.B. Góes, R.A. Halpin, N. Fedorova, A. Ransier, P.A. Weston, E.L. Durigon, et al. 2014. Isolation, propagation, genome analysis and epidemiology of $\mathrm{HKU}_{1}$ betacoronaviruses. The Journal of General Virology 95 (4): 836-848. https://doi.org/10.1099/vir.0. 059832-0.

Dong, B.Q., Liu, W., Fan, X.H., Vijaykrishna, D., Tang, X.C., Gao, F., Li, L.F., Li, G.J., Zhang, J.X., Yang, L.Q., Poon, L.L., Zhang, S.Y., Peiris,J.S., Smith, G.J., Chen, H., Guan, Y., 2007. Detection of a novel and highly divergent coronavirus from asian leopard cats and Chinese ferret badgers inSouthern China. Journal of virology 81 (13), 6920-6926. https://doi.org/10.1128/jvi.00299-07.

Dong, X., S. Liu, L.L. Zhu, X.Y. Wan, Q. Liu, L. Qiu, P.Z. Zou, Q.L. Zhang, and J. Huang. 2017. Complete genome sequence of an isolate of a novel genotype of yellow head virus from Fenneropenaeus chinensis indigenous in China. Archives of Virology 162 (4): 1149-1152. https://doi.org/10.1007/s00705-016-32 03-2.

Doyle, L.P., and L.M. Hutchings. 1946. A transmissible gastroenteritis in pigs. Journal of the American Veterinary Medical Association 108: 257-259.

Edwards, C.E., B.L. Yount, R.L. Graham, S.R. Leist, Y.J. Hou, K.H. Dinnon, A.C. Sims, J. Swanstrom, K. Gully, T.D. Scobey, et al. 2020. Swine acute diarrhea syndrome coronavirus replication in primary human cells reveals potential susceptibility to infection. Proceedings of the National Academy of Sciences USA 117 (43): 26915-26925. https://doi.org/10.1073/pnas.2001046117.

El-Sahly, H.M., R.L. Atmar, W.P. Glezen, and S.B. Greenberg. 2000. Spectrum of clinical illness in hospitalized patients with "common cold" virus infections. Clinical Infectious Diseases 31 (1): 96-100. https://doi.org/10.1086/313937.

Falsey, A.R., and E.E. Walsh. 2003. Novel coronavirus and severe acute respiratory syndrome. Lancet 361 (9366): 1312-1313. https://doi.org/10.1016/S0140-673 6(03)13084-X

Fang, S.G., S. Shen, F.P.L. Tay, and D.X. Liu. 2005. Selection of and recombination between minor variants lead to the adaptation of an avian coronavirus to primate cells. Biochemical and Biophysical Research Communications 336 (2): 417-423. https://doi.org/10.1016/j.bbrc.2005.08.105.

Fanoy, E.B., M.A. van der Sande, M. Kraaij-Dirkzwager, K. Dirksen, M. Jonges, W. van der Hoek, M.P. Koopmans, D. van der Werf, G. Sonder, C. van der Weijden, et al. 2014. Travel-related MERS-CoV cases: an assessment of exposures and risk factors in a group of Dutch travellers returning from the Kingdom of Saudi Arabia, May 2014. Emerging Themes in Epidemiology 11: 16. https://doi.org/10.1186/1742-7622-11-16.

Forni, D., R. Cagliani, M. Clerici, and M. Sironi. 2017. Molecular evolution of human coronavirus genomes. Trends in Microbiology 25 (1): 35-48. https://doi.org/1 0.1016/j.tim.2016.09.001

Ge, X.Y., J.L. Li, X.L. Yang, A.A. Chmura, G.J. Zhu, J.H. Epstein, J.K. Mazet, B. Hu, W. Zhang, C. Peng, et al. 2013. Isolation and characterization of a bat SARS-like coronavirus that uses the ACE2 receptor. Nature 503 (7477): 535-538. https:// doi.org/10.1038/nature12711.

Ge, X.Y., Y. Li, X.L. Yang, H.J. Zhang, P. Zhou, Y.Z. Zhang, and Z.L. Shi. 2012. Metagenomic analysis of viruses from bat fecal samples reveals many novel viruses in insectivorous bats in China. Journal of Virology 86 (8): 4620-4630. https://doi.org/10.1128/JVI.06671-11.

Ge, X.Y., W.H. Yang, J.H. Zhou, B. Li, W. Zhang, Z.L. Shi, and Y.Z. Zhang. 2017 Detection of alpha- and betacoronaviruses in rodents from Yunnan, China. Virology Journal 14 (1): 98. https://doi.org/10.1186/s12985-017-0766-9.

Gong, L., J. Li, Q.F. Zhou, Z.C. Xu, L. Chen, Y. Zhang, C.Y. Xue, Z.F. Wen, and Y.C. Cao. 2017. A new bat-HKU 2 -like coronavirus in swine, China, 2017. Emerging Infectious Diseases 23 (9): 1607-1609. https://doi.org/10.3201/eid2309.170915.

Gorham, J.R., J.F. Evermann, A. Ward, R. Pearson, D. Shen, G.R. Hartsough, and C. Leathers. 1990. Detection of coronavirus-like particles from mink with epizootic catarrhal gastroenteritis. Canadian Journal of Veterinary Research 54 (3): 383-384.

Graham, R.L., E.F. Donaldson, and R.S. Baric. 2013. A decade after SARS: strategies for controlling emerging coronaviruses. Nature Reviews. Microbiology 11 (12): 836-848. https://doi.org/10.1038/nrmicro3143.

Guan, Y., B.J. Zheng, Y.Q. He, X.L. Liu, Z.X. Zhuang, C.L. Cheung, S.W. Luo, P.H. Li, L. J. Zhang, Y.J. Guan, et al. 2003. Isolation and characterization of viruses related to the SARS coronavirus from animals in Southern China. Science 302 (5643): 276-278. https://doi.org/10.1126/science.1087139.

Gui, M., W.F. Song, H.X. Zhou, J.W. Xu, S.L. Chen, Y. Xiang, and X.Q. Wang. 2017. Cryo-electron microscopy structures of the SARS-CoV spike glycoprotein reveal a prerequisite conformational state for receptor binding. Cell Research 27 (1): 119-129. https://doi.org/10.1038/cr.2016.152.

Haagmans, B.L., S.H.S. Al Dhahiry, C.B.E.M. Reusken, V.S. Raj, M. Galiano, R. Myers, G.J. Godeke, M. Jonges, E. Farag, A. Diab, et al. 2014. Middle East respiratory syndrome coronavirus in dromedary camels: an outbreak investigation. The Lancet Infectious Diseases 14 (2): 140-145. https://doi.org/10.1016/S1473-3 099(13)70690-X.

Hamre, D., and J.J. Procknow. 1966. A new virus isolated from the human respiratory tract. Proceedings of the Society for Experimental Biology and Medicine 121 (1): 190-193. https://doi.org/10.3181/00379727-121-30734.

He, H.J., W.Y. Zhang, J.W. Liang, M. Lu, R.Y. Wang, G.R. Li, J.W. He, J. Chen, J. Chen, G. Xing, et al. 2020a. Etiology and genetic evolution of canine coronavirus circulating in five provinces of China, during 2018-2019. Microbial Pathogenesis 145: 104209. https://doi.org/10.1016/j.micpath.2020.104209.

He, W.T., X. Ji, W. He, S. Dellicour, S.L. Wang, G.R. Li, L.T. Zhang, M. Gilbert, H.N. Zhu, G. Xing, et al. 2020b. Genomic epidemiology, evolution, and transmission dynamics of porcine Deltacoronavirus. Molecular Biology and Evolution 37 (9): 2641-2654. https://doi.org/10.1093/molbev/msaa117.

Herrewegh, A.A.P.M., I. Smeenk, M.C. Horzinek, P.J.M. Rottier, and R.J. de Groot 1998. Feline coronavirus type II strains $79-1683$ and $79-1146$ originate from a double recombination between feline coronavirus type I and canine coronavirus. Journal of Virology 72 (5): 4508-4514. https://doi.org/10.1128/jvi. 72.5.4508-4514.1998.

Hewson, K.A., J. Ignjatovic, G.F. Browning, J.M. Devlin, and A.H. Noormohammadi. 2011. Infectious bronchitis viruses with naturally occurring genomic rearrangement and gene deletion. Archives of Virology 156 (2): 245-252. https://doi.org/10.1007/s00705-010-0850-6.

Hoet, A.E., and L.J. Saif. 2004. Bovine Torovirus (Breda virus) revisited. Animal Health Research Reviews 5 (2): 157-171. https://doi.org/10.1079/ahr200498.

Hou, Y.T., L.L. Zhang, M.T. Ren, Z.X. Han, J.F. Sun, Y. Zhao, and S.W. Liu. 2020. A highly pathogenic Gl-19 lineage infectious bronchitis virus originated from multiple recombination events with broad tissue tropism. Virus Research 285: 198002. https://doi.org/10.1016/j.virusres.2020.198002.

Hu, B., X.Y. Ge, L.F. Wang, and Z.L. Shi. 2015. Bat origin of human coronaviruses. Virology Journal 12: 221. https://doi.org/10.1186/s12985-015-0422-1.

Hu, B., H. Guo, P. Zhou, and Z.L. Shi. 2021. Characteristics of SARS-CoV-2 and COVID-19. Nature Reviews. Microbiology 19 (3): 141-154. https://doi.org/10.103 8/s41579-020-00459-7.

Hu, B., L.P. Zeng, X.L. Yang, X.Y. Ge, W. Zhang, B. Li, J.Z. Xie, X.R. Shen, Y.Z. Zhang, N. Wang, et al. 2017. Discovery of a rich gene pool of bat SARS-related coronaviruses provides new insights into the origin of SARS coronavirus. PLoS Pathogens 13 (11): e1006698. https://doi.org/10.1371/journal.ppat.1 006698.

Hu, D., C.Q. Zhu, L.L. Ai, T. He, Y. Wang, F.Q. Ye, L. Yang, C.X. Ding, X.H. Zhu, R. Lv, et al. 2018. Genomic characterization and infectivity of a novel SARS-like coronavirus in Chinese bats. Emerging Microbes \& Infections 7 (1): 1-10. https://doi.org/10.1038/s41426-018-0155-5.

Huang, C.L., Y.M. Wang, X.W. Li, L.L. Ren, J.P. Zhao, Y. Hu, L. Zhang, G.H. Fan, J.Y. Xu, X.Y. Gu, et al. 2020a. Clinical features of patients infected with 2019 novel coronavirus in Wuhan, China. Lancet 395 (10223): 497-506. https://doi.org/1 0.1016/S0140-6736(20)30183-5.

Huang, C.P., W.J. Liu, W. Xu, T. Jin, Y.Z. Zhao, J.D. Song, Y. Shi, W. Ji, H. Jia, Y.M. Zhou, et al. 2016. A bat-derived putative cross-family recombinant coronavirus with a reovirus gene. PLoS Pathogens 12 (9): e1005883. https:// doi.org/10.1371/journal.ppat.1005883.

Huang, M.J., C.C. Zou, Y. Liu, Z.L. Han, C.Y. Xue, and Y.C. Cao. 2020b. A novel low virulent respiratory infectious bronchitis virus originating from the recombination of QX, TW and 4/91 genotype strains in China. Veterinary Microbiology 242: 108579. https://doi.org/10.1016/j.vetmic.2020.108579.

International Committee on Taxonomy of Viruses Executive. 2020. The new scope of virus taxonomy: partitioning the virosphere into 15 hierarchical ranks. Nature Microbiology 5 (5): 668-674. https://doi.org/10.1038/s41564-020-0709-x.

Jackwood, M.W., D. Hall, and A. Handel. 2012. Molecular evolution and emergence of avian gammacoronaviruses. Infection, Genetics and Evolution 12 (6): 1305-1311. https://doi.org/10.1016/j.meegid.2012.05.003.

Janetanakit, T., M. Lumyai, N. Bunpapong, S. Boonyapisitsopa, S. Chaiyawong, N. Nonthabenjawan, S. Kesdaengsakonwut, and A. Amonsin. 2016. Porcine Deltacoronavirus, Thailand, 2015. Emerging Infectious Diseases 22 (4): 757-759. https://doi.org/10.3201/eid2204.151852.

Jonassen, C.M., T. Kofstad, I.L. Larsen, A. Løvland, K. Handeland, A. Follestad, and A. Lillehaug. 2005. Molecular identification and characterization of novel 
coronaviruses infecting graylag geese (Anser anser), feral pigeons (Columbia livia) and mallards (Anas platyrhynchos). The Journal of General Virology 86 (6): 1597-1607. https://doi.org/10.1099/vir.0.80927-0.

Kin, N., F. Miszczak, W. Lin, M.A. Gouilh, A. Vabret, and Consortium, E. 2015. Genomic analysis of 15 human coronaviruses OC43 (HCoV-OC43s) circulating in France from 2001 to 2013 reveals a high intra-specific diversity with new recombinant genotypes. Viruses 7 (5): 2358-2377. https://doi.org/10.3390/ v7052358.

King, A.M.Q., Lefkowitz, E.J., Mushegian, A.R., Adams, M.J., Dutilh, B.E., Gorbalenya, A.E., Harrach, B., Harrison, R.L., Junglen, S., Knowles, N.J., Kropinski, A.M., Krupovic, M., Kuhn, J.H., Nibert, M.L., Rubino, L., Sabanadzovic, S., Sanfaçon, H., Siddell, S.G., Simmonds, P., Varsani, A., Zerbini, F.M., Davison, A.J., 2018. Changes to taxonomy and the International Code of Virus Classification and Nomenclature ratified by the International Committee on Taxonomy of Viruses (2018). Archives of virology 163 (9), 2601-2631. https://doi.org/10.1007/ s00705-018-3847-1

Kint, J., M.A. Langereis, H.J. Maier, P. Britton, F.J. van Kuppeveld, J. Koumans, G.F. Wiegertjes, and M. Forlenza. 2016. Infectious bronchitis coronavirus limits interferon production by inducing a host shutoff that requires accessory protein 5b. Journal of Virology 90 (16): 7519-7528. https://doi.org/10.1128/JVl. 00627-16.

Korean Society of Infectious Diseases, Korean Society for Healthcare-associated Infection Control and Prevention. 2015. An unexpected outbreak of middle east respiratory syndrome coronavirus infection in the republic of Korea, 2015. Infectio \& Chemotherapy 47 (2): 120-122. https://doi.org/10.3947/ic.201 5.47.2.120.

Lam, T.T.Y., N. Jia, Y.W. Zhang, M.H.H. Shum, J.F. Jiang, H.C. Zhu, Y.G. Tong, Y.X. Shi, X.B. Ni, Y.S. Liao, et al. 2020. Identifying SARS-CoV-2-related coronaviruses in Malayan pangolins. Nature 583 (7815): 282-285. https://doi.org/10.1038/s41 586-020-2169-0.

Lamers, M.M., S.L. Smits, G.B. Hundie, L.B. Provacia, M. Koopmans, A.D.M.E. Osterhaus, B.L. Haagmans, and V.S. Raj. 2016. Naturally occurring recombination in ferret coronaviruses revealed by complete genome characterization. The Journal of General Virology 97 (9): 2180-2186. https://doi. org/10.1099/jgv.0.000520.

Latinne, A., B. Hu, K.J. Olival, G.J. Zhu, L.B. Zhang, H.Y. Li, A.A. Chmura, H.E. Field, C. Zambrana-Torrelio, J.H. Epstein, et al. 2020. Origin and cross-species transmission of bat coronaviruses in China. Nature Communications 11: 4235. https://doi.org/10.1038/s41467-020-17687-3

Lau, S.K.P., R.Y.Y. Fan, L.C. Zhu, K.S.M. Li, A.C.P. Wong, H.K.H. Luk, E.Y.M. Wong, C.S. F. Lam, G.C.S. Lo, J. Fung, et al. 2021. Isolation of MERS-related coronavirus from lesser bamboo bats that uses $\mathrm{DPP}_{4}$ and infects human-DPP 4 -transgenic mice. Nature Communications 12: 216. https://doi.org/10.1038/s41467-020-2 0458-9

Lau, S.K.P., K.S.M. Li, A.K.L. Tsang, C.T. Shek, M. Wang, G.K.Y. Choi, R. Guo, B.H.L Wong, R.W.S. Poon, C.S.F. Lam, et al. 2012. Recent transmission of a novel Alphacoronavirus, bat coronavirus HKU10, from leschenault's rousettes to Pomona leaf-nosed bats: first evidence of interspecies transmission of coronavirus between bats of different suborders. Journal of Virology 86 (21): 11906-11918. https://doi.org/10.1128/jvi.01305-12.

Lau, S.K.P., H.K.H. Luk, A.C.P. Wong, R.Y.Y. Fan, C.S.F. Lam, K.S.M. Li, S.S. Ahmed, F. W.N. Chow, J.P. Cai, X. Zhu, et al. 2019a. Identification of a novel Betacoronavirus (merbecovirus) in Amur hedgehogs from China. Viruses 11 (11): 980. https://doi.org/10.3390/v11110980.

Lau, S.K.P., A.C.P. Wong, L.B. Zhang, H.K.H. Luk, J.S.L. Kwok, S.S. Ahmed, J.P. Cai, P.S.H. Zhao J.L.L. Teng, S.K.W. Tsui, et al. 2019b. Novel bat alphacoronaviruses in Southern China support Chinese horseshoe bats as an important reservoir for potential novel coronaviruses. Viruses 11 (5): 423. https://doi.org/10.3390/v11050423.

Lau, S.K.P., E.Y.M. Wong, C.C. Tsang, S.S. Ahmed, R.K.H. Au-Yeung, K.Y. Yuen, U. Wernery, and P.C.Y. Woo. 2018a. Discovery and sequence analysis of four deltacoronaviruses from birds in the middle east reveal interspecies jumping with recombination as a potential mechanism for avian-to-avian and avianto-mammalian transmission. Journal of Virology 92 (15): e00265-e00218. https://doi.org/10.1128/jvi.00265-18.

Lau, S.K.P., P.C.Y. Woo, K.S.M. Li, Y. Huang, M. Wang, C.S.F. Lam, H.F. Xu, R.T. Guo, K.H. Chan, B.J. Zheng, et al. 2007. Complete genome sequence of bat coronavirus $\mathrm{HKU}_{2}$ from Chinese horseshoe bats revealed a much smaller spike gene with a different evolutionary lineage from the rest of the genome. Virology 367 (2): 428-439. https://doi.org/10.1016/j.virol.2007.06.009.

Lau, S.K.P., P.C.Y. Woo, K.S.M. Li, A.K.L. Tsang, R.Y.Y. Fan, H.K.H. Luk, J.P. Cai, K.H. Chan, B.J. Zheng, M. Wang, et al. 2015. Discovery of a novel coronavirus,
China Rattus coronavirus HKU24, from Norway rats supports the murine origin of Betacoronavirus 1 and has implications for the ancestor of Betacoronavirus lineage A. Journal of Virology 89 (6): 3076-3092. https://doi. org/10.1128/JVI.02420-14.

Lau, S.K.P., L.B. Zhang, H.K.H. Luk, L.F. Xiong, X.W. Peng, K.S.M. Li, X.Y. He, P.S.H. Zhao, R.Y.Y. Fan, A.C.P. Wong, et al. 2018b. Receptor usage of a novel bat lineage C Betacoronavirus reveals evolution of middle east respiratory syndrome-related coronavirus spike proteins for human dipeptidyl peptidase 4 binding. The Journal of Infectious Diseases 218 (2): 197-207. https://doi. org/10.1093/infdis/jiy018.

Lauber, C., J. Ziebuhr, S. Junglen, C. Drosten, F. Zirkel, P.T. Nga, K. Morita, E.J. Snijder, and A.E. Gorbalenya. 2012. Mesoniviridae: a proposed new family in the order Nidovirales formed by a single species of mosquito-borne viruses. Archives of Virology 157 (8): 1623-1628. https://doi.org/10.1007/s00705-012-12 95-x.

Lauck, M., S.V. Alkhovsky, Y. Bào, A.L. Bailey, Z.V. Shevtsova, A.M. Shchetinin, T.V. Vishnevskaya, M.G. Lackemeyer, E. Postnikova, S. Mazur, et al. 2015. Historical outbreaks of Simian hemorrhagic fever in captive macaques were caused by distinct arteriviruses. Journal of Virology 89 (15): 8082-8087. https://doi.org/1 0.1128/JVI.01046-15.

Lauck, M., S.D. Sibley, D. Hyeroba, A. Tumukunde, G. Weny, C.A. Chapman, N. Ting, W.M. Switzer, J.H. Kuhn, T.C. Friedrich, et al. 2013. Exceptional Simian hemorrhagic fever virus diversity in a wild African primate community. Journal of Virology 87 (1): 688-691. https://doi.org/10.1128/JVI.02433-12.

Le, V.P., S. Song, B.H. An, G.N. Park, N.T. Pham, D.Q. Le, V.T. Nguyen, T.T.H. Vu, K.S. Kim, S. Choe, et al. 2018. A novel strain of porcine Deltacoronavirus in Vietnam. Archives of Virology 163 (1): 203-207. https://doi.org/10.1007/s00705017-3594-8.

Lee, S., and C. Lee. 2014. Complete genome characterization of Korean porcine Deltacoronavirus strain KOR/KNU14-04/2014. Genome Announcements 2 (6): e01191-e01114. https://doi.org/10.1128/genomea.01191-14.

Lefkowitz, E.J., D.M. Dempsey, R.C. Hendrickson, R.J. Orton, S.G. Siddell, and D.B. Smith. 2018. Virus taxonomy: the database of the international International Committee on Taxonomy of Viruses Executive on taxonomy of viruses (ICTV). Nucleic Acids Research 46 (D1): D708-D717. https://doi.org/10.1093/nar/ gkx932.

Lewis, C.S., E. Porter, D. Matthews, A. Kipar, S. Tasker, C.R. Helps, and S.G. Siddell. 2015. Genotyping coronaviruses associated with feline infectious peritonitis. The Journal of General Virology 96 (6): 1358-1368. https://doi.org/10.1099/vir.0 000084.

Li, C.Q., Q.J. Liu, F.Z. Kong, D.H. Guo, J.J. Zhai, M.J. Su, and D.B. Sun. 2019. Circulation and genetic diversity of Feline coronavirus type I and II from clinically healthy and FIP-suspected cats in China. Transboundary and Emerging Diseases 66 (2): 763-775. https://doi.org/10.1111/tbed.13081.

Li, G., Q. Chen, K.M. Harmon, K.J. Yoon, K.J. Schwartz, M.J. Hoogland, P.C. Gauger, R.G. Main, and J. Zhang. 2014. Full-length genome sequence of porcine Deltacoronavirus strain USA/IA/2014/8734. Genome Announcements 2 (2): e00278-e00214. https://doi.org/10.1128/genomea.00278-14.

Li, H., B. Zhang, H. Yue, and C. Tang. 2020a. First detection and genomic characteristics of bovine Torovirus in dairy calves in China. Archives of Virology 165 (7): 1577-1583. https://doi.org/10.1007/s00705-020-04657-9.

Li, J.Y., C.H. Liao, Q. Wang, Y.J. Tan, R. Luo, Y. Qiu, and X.Y. Ge. 2020b. The ORF6, $\mathrm{ORF}_{8}$ and nucleocapsid proteins of SARS-CoV-2 inhibit type I interferon signaling pathway. Virus Research 286: 198074. https://doi.org/10.1016/j. virusres.2020.198074.

Li, J.Y., Z. You, Q. Wang, Z.J. Zhou, Y. Qiu, R. Luo, and X.Y. Ge. 2020c. The epidemic of 2019-novel-coronavirus (2019-nCoV) pneumonia and insights for emerging infectious diseases in the future. Microbes and Infection 22 (2): 8085. https://doi.org/10.1016/j.micinf.2020.02.002.

Li, T.T., J.Y. Li, T. Huang, and X.Y. Ge. 2017. Complete genome sequence of a novel strain of infectious bronchitis virus, isolated from chickens in China in 2016. Genome Announcements 5 (45): e01277-e01217. https://doi.org/10.112 8/genomea.01277-17.

Li, W.D., Z.L. Shi, M. Yu, W.Z. Ren, C. Smith, J.H. Epstein, H.Z. Wang, G. Crameri, Z.H. Hu, H.J. Zhang, et al. 2005. Bats are natural reservoirs of SARS-like coronaviruses. Science 310 (5748): 676-679. https://doi.org/10.1126/ science.1118391.

Li, W.H., M.J. Moore, N. Vasilieva, J.H. Sui, S.K. Wong, M.A. Berne, M. Somasundaran, J.L. Sullivan, K. Luzuriaga, T.C. Greenough, et al. 2003. Angiotensin-converting enzyme 2 is a functional receptor for the SARS coronavirus. Nature 426 (6965): 450-454. https://doi.org/10.1038/nature02145. 
Lorsirigool, A., K. Saeng-Chuto, G. Temeeyasen, A. Madapong, T. Tripipat, M. Wegner, A. Tuntituvanont, M. Intrakamhaeng, and D. Nilubol. 2016. The first detection and full-length genome sequence of porcine Deltacoronavirus isolated in Lao PDR. Archives of Virology 161 (10): 2909-2911. https://doi.org/1 0.1007/s00705-016-2983-8

Lu, G.W., Q.H. Wang, and G.F. Gao. 2015. Bat-to-human: spike features determining 'host jump' of coronaviruses SARS-COV, MERS-CoV, and beyond. Trends in Microbiology 23 (8): 468-478. https://doi.org/10.1016/j.tim.2015.06. 003.

Lu, R.J., X. Zhao, J. Li, P.H. Niu, B. Yang, H.L. Wu, W.L. Wang, H. Song, B.Y. Huang, N. Zhu, et al. 2020. Genomic characterisation and epidemiology of 2019 novel coronavirus: implications for virus origins and receptor binding. Lancet 395 (10224): 565-574. https://doi.org/10.1016/S0140-6736(20)30251-8.

Luo, Y., Y. Chen, R. Geng, B. Li, J. Chen, K. Zhao, X.S. Zheng, W. Zhang, P. Zhou, X. L. Yang, et al. 2020. Broad cell tropism of SADS-CoV in vitro implies its potential cross-species infection risk. Virologica Sinica. Online ahead of print. https://doi.org/10.1007/s12250-020-00321-3.

Lyu, S.J., X.M. Yuan, H.Q. Zhang, X.Y. Hang, Y.L. Li, W.D. Shi, L. Liu, Z. Yu, and Y.L. Wu. 2020. Transcriptome profiling analysis of lung tissue of Chinese soft-shell turtle infected by Trionyx sinensis Hemorrhagic Syndrome Virus. Fish \& Shellfish Immunology 98: 653-660. https://doi.org/10.1016/j.fsi.201 9.10.061.

Lyu, S.J., X.M. Yuan, H.Q. Zhang, W.D. Shi, X.Y. Hang, L. Liu, Z. Cao, and Y.L. Wu. 2019. Complete genome sequence and analysis of a new lethal Arterivirus, Trionyx sinensis hemorrhagic syndrome virus (TSHSV), amplified from an infected Chinese softshell turtle. Archives of Virology 164 (10): 2593-2597. https://doi.org/10.1007/s00705-019-04324-8.

Ma, H.W., R.M. Overstreet, and J.A. Jovonovich. 2009. Daggerblade grass shrimp (Palaemonetes pugio): a reservoir host for yellow-head virus (YHV). Journal of Invertebrate Pathology 101 (2): 112-118. https://doi.org/10.1016/j.jip.2009.04. 002.

Mailles, A., K. Blanckaert, P. Chaud, S. Van Der Werf, B. Lina, V. Caro, C. Campese, B. Guery, H. Prouvost, X. Lemaire, et al. 2013. First cases of Middle East Respiratory Syndrome Coronavirus (MERS-CoV) infections in France, investigations and implications for the prevention of human-to-human transmission, France, May 2013. Euro Surveillance 18 (24): 20502.

Marandino, A., G. Tomás, Y. Panzera, G. Greif, A. Parodi-Talice, M. Hernández, C. Techera, D. Hernández, and R. Pérez. 2017. Whole-genome characterization of Uruguayan strains of avian infectious bronchitis virus reveals extensive recombination between the two major South American lineages. Infection, Genetics and Evolution 54: 245-250. https://doi.org/10.1016/j.meegid.2017.07. 009.

McIntosh, K., W.B. Becker, and R.M. Chanock. 1967. Growth in suckling-mouse brain of "IBV-like" viruses from patients with upper respiratory tract disease. Proceedings of the National Academy of Sciences USA 58 (6): 2268-2273. https://doi.org/10.1073/pnas.58.6.2268.

Memish, Z.A., M. Cotten, B. Meyer, SJ. Watson, A.J. Alsahafi, A.A. Al Rabeeah, V.M. Corman, A. Sieberg, H.Q. Makhdoom, A. Assiri, et al. 2014. Human infection with MERS coronavirus after exposure to infected camels, Saudi Arabia, 2013. Emerging Infectious Diseases 20 (6): 1012-1015. https://doi.org/10.3201/eid2006.140402.

Mihindukulasuriya, KA., G. Wu, J. St Leger, R.W. Nordhausen, and D. Wang. 2008. Identification of a novel coronavirus from a beluga whale by using a panviral microarray. Journal of Virology 82 (10): 5084-5088. https:/doi.org/10.1128/JVI.02722-07.

Müller, M.A., V.M. Corman, J. Jores, B. Meyer, M. Younan, A. Liljander, B.J. Bosch, E. Lattwein, M. Hilali, B.E. Musa, et al. 2014. MERS coronavirus neutralizing antibodies in camels, Eastern Africa, 1983-1997. Emerging Infectious Diseases 20 (12): 2093-2095. https://doi.org/10.3201/eid2012.141026.

Nukoolkarn, V., V.S. Lee, M. Malaisree, O. Aruksakulwong, and S. Hannongbua. 2008. Molecular dynamic simulations analysis of ritronavir and lopinavir as SARS-CoV 3CLpro inhibitors. Journal of Theoretical Biology 254 (4): 861-867. https://doi.org/10.1016/j.jtbi.2008.07.030.

O'Dea, M.A., B. Jackson, C. Jackson, P. Xavier, and K. Warren. 2016. Discovery and partial genomic characterisation of a novel nidovirus associated with respiratory disease in wild shingleback lizards (Tiliqua rugosa). PLoS One 11 (11): e0165209. https://doi.org/10.1371/journal.pone.0165209.

Ommeh, S., W. Zhang, A. Zohaib, J. Chen, H.J. Zhang, B. Hu, X.Y. Ge, X.L. Yang, M. Masika, V. Obanda, et al. 2018. Genetic evidence of middle east respiratory syndrome coronavirus (MERS-cov) and widespread seroprevalence among camels in Kenya. Virologica Sinica 33 (6): 484-492. https:/doi.org/10.1007/s12250-018-0076-4.

Oude Munnink, B.B., R.S. Sikkema, D.F. Nieuwenhuijse, R.J. Molenaar, E. Munger, R, Molenkamp, A. van der Spek, P. Tolsma, A. Rietveld, M. Brouwer, et al. 2021.
Transmission of SARS-CoV-2 on mink farms between humans and mink and back to humans. Science 371 (6525): 172-177. https://doi.org/10.1126/ science.abe5901.

Pan, Y.F., X.Y. Tian, P. Qin, B. Wang, P.W. Zhao, Y.L. Yang, L.X. Wang, D.D. Wang, Y. H. Song, X.B. Zhang, et al. 2017. Discovery of a novel swine enteric Alphacoronavirus (SeACoV) in Southern China. Veterinary Microbiology 211: 15-21. https://doi.org/10.1016/j.vetmic.2017.09.020.

Papineau, A., Y. Berhane, T.N. Wylie, K.M. Wylie, S. Sharpe, and O. Lung. 2019. Genome organization of Canada goose coronavirus, A novel species identified in a mass Die-off of Canada geese. Scientific Reports 9 (1): 5954. https://doi.org/10.1038/s41598-019-42355-y.

Parry, J. 2003. WHO warns that death rate from SARS could reach 10\%. British Medical Journal Clinical Research Edition 326 (7397): 999. https://doi.org/1 0.1136/bmj.326.7397.999/a.

Paskey, A.C., J.H.J. Ng, G.K. Rice, W.N. Chia, C.W. Philipson, R.J.H. Foo, R.Z. Cer, K.A. Long, M.R. Lueder, X.F. Lim, et al. 2020. Detection of recombinant Rousettus bat coronavirus GCCDC1 in lesser dawn bats (Eonycteris spelaea) in Singapore. Viruses 12 (5): 539. https://doi.org/10.3390/v12050539.

Pensaert, M.B., and P. Bouck. 1978. A new coronavirus-like particle associated with diarrhea in swine. Archives of Virology 58 (3): 243-247. https://doi.org/10.1 007/BF01317606.

Pfefferle, S., S. Oppong, J.F. Drexler, F. Gloza-Rausch, A. Ipsen, A. Seebens, M.A. Müller, A. Annan, P. Vallo, Y. Adu-Sarkodie, et al. 2009. Distant relatives of severe acute respiratory syndrome coronavirus and close relatives of human coronavirus $229 \mathrm{E}$ in bats, Ghana. Emerging Infectious Diseases 15 (9): $1377-$ 1384. https://doi.org/10.3201/eid1509.090224.

Pignatelli, J., L. Grau-Roma, M. Jiménez, J. Segalés, and D. Rodríguez. 2010. Longitudinal serological and virological study on porcine Torovirus (PToV) in piglets from Spanish farms. Veterinary Microbiology 146 (3/4): 260-268. https://doi.org/10.1016/j.vetmic.2010.05.023.

Posthuma, C.C., D.D. Nedialkova, J.C. Zevenhoven-Dobbe, J.H. Blokhuis, A.E. Gorbalenya, and E.J. Snijder. 2006. Site-directed mutagenesis of the Nidovirus replicative endoribonuclease NendoU exerts pleiotropic effects on the Arterivirus life cycle. Journal of Virology 80 (4): 1653-1661. https://doi.org/1 0.1128/JVI.80.4.1653-1661.2006.

Posthuma, C.C., K.W. Pedersen, Z.C. Lu, R.G. Joosten, N. Roos, J.C. ZevenhovenDobbe, and E.J. Snijder. 2008. Formation of the Arterivirus replication/ transcription complex: a key role for nonstructural protein 3 in the remodeling of intracellular membranes. Journal of Virology 82 (9): 4480-4491. https://doi.org/10.1128/JVI.02756-07.

Pratelli, A., V. Martella, N. Decaro, A. Tinelli, M. Camero, F. Cirone, G. Elia, A. Cavalli, M. Corrente, G. Greco, et al. 2003. Genetic diversity of a canine coronavirus detected in pups with diarrhoea in Italy. Journal of Virological Methods 110 (1): 9-17. https://doi.org/10.1016/S0166-0934(03)00081-8.

Pringle, C.R. 1996. Virus taxonomy 1996- a bulletin from the xth international congress of virology in Jerusalem. Archives of Virology 141 (11): 2251-2256. https://doi.org/10.1007/BF01718231.

Pusterla, N., R. Vin, C. Leutenegger, L.D. Mittel, and T.J. Divers. 2016. Equine coronavirus: an emerging enteric virus of adult horses. Equine Veterinary Education 28 (4): 216-223. https://doi.org/10.1111/eve.12453.

Qin, P., E.Z. Du, W.T. Luo, Y.L. Yang, Y.Q. Zhang, B. Wang, and Y.W. Huang. 2019. Characteristics of the life cycle of porcine Deltacoronavirus (PDCoV) in vitro: replication kinetics, cellular ultrastructure and virion morphology, and evidence of inducing autophagy. Viruses 11 (5): 455. https://doi.org/10.3390/ V11050455.

Reddy, V.R.A.P., S. Theuns, I.D.M. Roukaerts, M. Zeller, J. Matthijnssens, and H.J. Nauwynck. 2015. Genetic characterization of the Belgian nephropathogenic infectious bronchitis virus (NIBV) reference strain B1648. Viruses 7 (8): 44884506. https://doi.org/10.3390/v7082827.

Reusken, C.B., B.L. Haagmans, M.A. Müller, C. Gutierrez, G.J. Godeke, B. Meyer, D. Muth, V.S. Raj, L.S.D. Vries, V.M. Corman, et al. 2013. Middle East respiratory syndrome coronavirus neutralising serum antibodies in dromedary camels: a comparative serological study. The Lancet Infectious Diseases 13 (10): 859-866. https://doi.org/10.1016/S1473-3099(13)70164-6.

Reusken, C.B.E.M., L. Messadi, A. Feyisa, H. Ularamu, G.J. Godeke, A. Danmarwa, F.F. Dawo, M. Jemli, S. Melaku, D. Shamaki, et al. 2014. Geographic distribution of MERS coronavirus among dromedary camels, Africa. Emerging Infectious Diseases 20 (8): 1370-1374. https://doi.org/10.3201/eid2008.140590.

Saberi, A., A.A. Gulyaeva, J.L. Brubacher, P.A. Newmark, and A.E. Gorbalenya. 2018. A planarian nidovirus expands the limits of RNA genome size. PLOS Pathogens 14 (11): e1007314. https://doi.org/10.1371/journal.ppat.1007314. 
Sabir, J.S.M., T.T.Y. Lam, M.M.M. Ahmed, L. Li, Y. Shen, S.E.M. Abo-Aba, M.I. Qureshi, M. Abu-Zeid, Y. Zhang, M.A. Khiyami, et al. 2016. Co-circulation of three camel coronavirus species and recombination of MERS-CoVs in Saudi Arabia. Science 351 (6268): 81-84. https://doi.org/10.1126/science.aac8608.

Schütze, H., R. Ulferts, B. Schelle, S. Bayer, H. Granzow, B. Hoffmann, T.C. Mettenleiter, and J. Ziebuhr. 2006. Characterization of White bream virus reveals a novel genetic cluster of nidoviruses. Journal of Virology 80 (23): 11598-11609. https://doi.org/10.1128/JVI.01758-06.

Shi, M., X.D. Lin, X. Chen, J.H. Tian, L.J. Chen, K. Li, W. Wang, J.S. Eden, J.J. Shen, L. Liu, et al. 2018. The evolutionary history of vertebrate RNA viruses. Nature 556 (7700): 197-202. https://doi.org/10.1038/s41586-018-0012-7.

Shi, M., X.D. Lin, J.H. Tian, L.J. Chen, X. Chen, C.X. Li, X.C. Qin, J. Li, J.P. Cao, J.S. Eden, et al. 2016. Redefining the invertebrate RNA virosphere. Nature 540 (7634): 539-543. https://doi.org/10.1038/nature20167.

Siu, K.L., C.P. Chan, K.H. Kok, P.C.Y. Woo, and D.Y. Jin. 2014. Comparative analysis of the activation of unfolded protein response by spike proteins of severe acute respiratory syndrome coronavirus and human coronavirus $\mathrm{HKU}_{1}$. Cell \& Bioscience 4 (1): 3. https://doi.org/10.1186/2045-3701-4-3.

Song, D., X. Zhou, Q. Peng, Y. Chen, F. Zhang, T. Huang, T. Zhang, A. Li, D. Huang, Q. Wu, et al. 2015. Newly emerged porcine Deltacoronavirus associated with diarrhoea in swine in China: identification, prevalence and full-length genome sequence analysis. Transboundary and Emerging Diseases 62 (6): 575-580. https://doi.org/10.1111/tbed.12399.

Soowannayan, C., N. Chanarpakorn, M. Phanthura, N. Deekhlai, C. Kunasol, and S. Sriurairatana. 2013. N-Linked glycosylation is essential for the yellow head virus replication cycle. The Journal of General Virology 94 (11): 2458-2468. https://doi.org/10.1099/vir.0.054379-0.

Stadler, K., V. Masignani, M. Eickmann, S. Becker, S. Abrignani, H.D. Klenk, and R. Rappuoli. 2003. SARS-beginning to understand a new virus. Nature Reviews. Microbiology 1 (3): 209-218. https://doi.org/10.1038/nrmicro775.

Stenglein, M.D., E.R. Jacobson, E.J. Wozniak, J.F.X. Wellehan, A. Kincaid, M. Gordon, B.F. Porter, W. Baumgartner, S. Stahl, K. Kelley, et al. 2014. Ball Python nidovirus: a candidate etiologic agent for severe respiratory disease in Python regius. mBio 5 (5): e01484-e01414. https://doi.org/10.1128/mBio.01484-14.

Stewart, H., K. Brown, A.M. Dinan, N. Irigoyen, E.J. Snijder, and A.E. Firth. 2018. Transcriptional and translational landscape of equine torovirus. Journal of Virology 92 (17): e00589-e00518. https://doi.org/10.1128/JVI.00589-18.

Subudhi, S., N. Rapin, T.K. Bollinger, J.E. Hill, M.E. Donaldson, C.M. Davy, L. Warnecke, J.M. Turner, C.J. Kyle, C.K.R. Willis, et al. 2017. A persistently infecting coronavirus in hibernating Myotis lucifugus, the North American little brown bat. The Journal of General Virology 98 (9): 2297-2309. https://doi. org/10.1099/jgv.0.000898

Sun, H., D.L. Lan, L.F. Lu, M.L. Chen, C.S. Wang, and X.G. Hua. 2014. Molecular characterization and phylogenetic analysis of the genome of porcine Torovirus. Archives of Virology 159 (4): 773-778. https://doi.org/10.1007/s00705-013-1861-X.

Sun, L., G.H. Zhang, J.W. Jiang, J.D. Fu, T. Ren, W.S. Cao, C.A. Xin, M. Liao, and W.J. Liu. 2007. A Massachusetts prototype like coronavirus isolated from wild peafowls is pathogenic to chickens. Virus Research 130 (1/2): 121-128. https:// doi.org/10.1016/j.virusres.2007.06.003.

Suzuki, T., T. Shibahara, N. Imai, T. Yamamoto, and S. Ohashi. 2018. Genetic characterization and pathogenicity of Japanese porcine Deltacoronavirus. Infection, Genetics and Evolution 61: 176-182. https://doi.org/10.1016/j. meegid.2018.03.030.

Tang, X.C., J.X. Zhang, S.Y. Zhang, P. Wang, X.H. Fan, L.F. Li, G. Li, B.Q. Dong, W. Liu, C.L. Cheung, et al. 2006. Prevalence and genetic diversity of coronaviruses in bats from China. Journal of Virology 80 (15): 7481-7490. https://doi.org/10.1128/JVI.00697-06.

Tao, Y., M. Shi, C. Chommanard, K. Queen, J. Zhang, W. Markotter, I.V. Kuzmin, E.C. Holmes, and S.X. Tong. 2017. Surveillance of bat coronaviruses in Kenya identifies relatives of human coronaviruses NL63 and 229E and their recombination history. Journal of Virology 91 (5): e01953-e01916. https://doi. org/10.1128/jvi.01953-16.

The Health Protection Agency Uk Novel Coronavirus Investigation Team, C., 2013. Evidence of person-to-person transmission within a family cluster of novel coronavirus infections, United Kingdom, February 2013. Eurosurveillance 18 (11), 20427. https://doi.org/10.2807/ese.18.11.20427-en.

Thor, S.W., D.A. Hilt, J.C. Kissinger, A.H. Paterson, and M.W. Jackwood. 2011. Recombination in avian gamma-coronavirus infectious bronchitis virus. Viruses 3 (9): 1777-1799. https://doi.org/10.3390/v3091777.

Tokarz, R., S. Sameroff, R.A. Hesse, B.M. Hause, A. Desai, K. Jain, and W. Ian Lipkin. 2015. Discovery of a novel nidovirus in cattle with respiratory disease. The
Journal of General Virology 96 (8): 2188-2193. https://doi.org/10.1099/vir.0 000166.

Tsoleridis, T., J. Chappell, O. Onianwa, D. Marston, A. Fooks, E. Monchatre-Leroy, G. Umhang, M. Müller, J. Drexler, C. Drosten, et al. 2019. Shared common ancestry of rodent alphacoronaviruses sampled globally. Viruses 11 (2): 125. https://doi.org/10.3390/v11020125.

van der Hoek, L., K. Pyrc, M.F. Jebbink, W. Vermeulen-Oost, R.J.M. Berkhout, K.C. Wolthers, P.M.E. Wertheim-van Dillen, J. Kaandorp, J. Spaargaren, and B. Berkhout. 2004. Identification of a new human coronavirus. Nature Medicine 10 (4): 368-373. https://doi.org/10.1038/nm1024.

van Marle, G., J.C. Dobbe, A.P. Gultyaev, W. Luytjes, W.J. Spaan, and E.J. Snijder. 1999. Arterivirus discontinuous mRNA transcription is guided by base pairing between sense and antisense transcription-regulating sequences. Proceedings of the National Academy of Sciences USA 96 (21): 12056-12061. https://doi. org/10.1073/pnas.96.21.12056.

Vanmechelen, B., V. Vergote, L. Laenen, F.R. Koundouno, J.A. Bore, J. Wada, J.H. Kuhn, M.W. Carroll, and P. Maes. 2018. Expanding the Arterivirus host spectrum: olivier's shrew virus 1, A novel Arterivirus discovered in African giant shrews. Scientific Reports 8 (1): 11171. https://doi.org/10.1038/s41598-018-29560-x.

Vasilakis, N., H. Guzman, C. Firth, N.L. Forrester, S.G. Widen, T.G. Wood, S.L. Rossi, E. Ghedin, V. Popov, K.R. Blasdell, et al. 2014. Mesoniviruses are mosquitospecific viruses with extensive geographic distribution and host range. Virology Journal 11 (1): 1-12. https://doi.org/10.1186/1743-422X-11-97.

Vetterlein, W., and R. Hesse. 1965. Electron microscopic picture of viral hepatitis in man and mouse. Archiv für Experimentelle Veterinaermedizin 19: 231-240.

Vlasova, A.N., R. Halpin, S. Wang, E. Ghedin, D.J. Spiro, and L.J. Saif. 2011. Molecular characterization of a new species in the genus Alphacoronavirus associated with mink epizootic catarrhal gastroenteritis. The Journal of General Virology 92 (6): 1369-1379. https://doi.org/10.1099/vir.0.025353-0.

Walker, P.J., S.G. Siddell, E.J. Lefkowitz, A.R. Mushegian, D.M. Dempsey, B.E. Dutilh, B. Harrach, R.L. Harrison, R.C. Hendrickson, S. Junglen, et al. 2019. Changes to virus taxonomy and the international code of virus classification and nomenclature ratified by the group of viruses (2019). Archives of Virology 164 (9): 2417-2429. https://doi.org/10.1007/s00705-019-04306-w.

Wang, B., Y. Liu, C.M. Ji, Y.L. Yang, Q.Z. Liang, P.W. Zhao, L.D. Xu, X.M. Lei, W.T. Luo, P. Qin, et al. 2018. Porcine Deltacoronavirus engages the transmissible gastroenteritis virus functional receptor porcine aminopeptidase $\mathrm{N}$ for infectious cellular entry. Journal of Virology 92 (12): e00318-e00318. https:// doi.org/10.1128/jvi.00318-18.

Wang, L., and Y. Zhang. 2017. Genomic characterization of a new PRCV variant, United States, 2014. Transboundary and Emerging Diseases 64 (2): 672-674. https://doi.org/10.1111/tbed.12400.

Wang, L.Y., B. Byrum, and Y. Zhang. 2014a. Porcine coronavirus HKU15 detected in 9 US states, 2014. Emerging Infectious Diseases 20 (9): 1594-1595. https:// doi.org/10.3201/eid2009.140756.

Wang, Q., Y. Qiu, J.Y. Li, C.H. Liao, Z.J. Zhou, and X.Y. Ge. 2020a. Receptor utilization of angiotensin-converting enzyme 2 (ACE2) indicates a narrower host range of SARS-CoV-2 than that of SARS-CoV. Transboundary and Emerging Diseases 13: 10.1111/tbed.13792. https://doi.org/10.1111/tbed.13 792.

Wang, Q., Y. Qiu, J.Y. Li, Z.J. Zhou, C.H. Liao, and X.Y. Ge. 2020b. A unique protease cleavage site predicted in the spike protein of the novel pneumonia coronavirus (2019-nCoV) potentially related to viral transmissibility. Virologica Sinica 35 (3): 337-339. https://doi.org/10.1007/s122 50-020-00212-7.

Wang, Q., Z.J. Zhou, Z. You, D.Y. Wu, S.J. Liu, W.L. Zhang, K.R. Fan, R. Luo, Y. Qiu, and X.Y. Ge. 2021. Epidemiology and evolution of novel deltacoronaviruses in birds in central China. Transboundary and Emerging Diseases. https://doi. org/10.1111/tbed.14029.

Wang, Q.H., J.X. Qi, Y. Yuan, Y.F. Xuan, P.C. Han, Y.H. Wan, W. Ji, Y. Li, Y. Wu, J.W. Wang, et al. 2014b. Bat origins of MERS-CoV supported by bat coronavirus $\mathrm{HKU}_{4}$ usage of human receptor CD26. Cell Host \& Microbe 16 (3): 328-337. https://doi.org/10.1016/j.chom.2014.08.009.

Wang, W., X.D. Lin, W.P. Guo, R.H. Zhou, M.R. Wang, C.Q. Wang, S. Ge, S.H. Mei, M. H. Li, M. Shi, et al. 2015. Discovery, diversity and evolution of novel coronaviruses sampled from rodents in China. Virology 474: 19-27. https:// doi.org/10.1016/j.virol.2014.10.017.

Wang, W., X.D. Lin, Y. Liao, X.Q. Guan, W.P. Guo, J.G. Xing, E.C. Holmes, and Y.Z. Zhang. 2017. Discovery of a highly divergent coronavirus in the Asian house shrew from China illuminates the origin of the Alphacoronaviruses. Journal of Virology 91 (17): e00764-e00717. https://doi.org/10.1128/JVI.00764-17. 
WHO n.d., https://covid19.who.int/

Wise, A.G., M. Kiupel, M.M. Garner, A.K. Clark, and R.K. Maes. 2010. Comparative sequence analysis of the distal one-third of the genomes of a systemic and an enteric ferret coronavirus. Virus Research 149 (1): 42-50. https://doi.org/1 0.1016/j.virusres.2009.12.011.

Wise, A.G., M. Kiupel, and R.K. Maes. 2006. Molecular characterization of a novel coronavirus associated with epizootic catarrhal enteritis (ECE) in ferrets. Virology 349 (1): 164-174. https://doi.org/10.1016/j.virol.2006.01.031.

Wong, A., X. Li, S. Lau, and P. Woo. 2019. Global epidemiology of bat coronaviruses. Viruses 11 (2): 174. https://doi.org/10.3390/v11020174.

Woo, P.C., M. Wang, S.K. Lau, H. Xu, R.W. Poon, R. Guo, B.H. Wong, K. Gao, H.W. Tsoi, Y. Huang, et al. 2007. Comparative analysis of twelve genomes of three novel group $2 \mathrm{c}$ and group $2 \mathrm{~d}$ coronaviruses reveals unique group and subgroup features. Journal of Virology 81 (4): 1574-1585. https://doi.org/1 0.1128/jvi.02182-06.

Woo, P.C.Y., S.K.P. Lau, C.M. Chu, K.H. Chan, H.W. Tsoi, Y. Huang, B.H.L. Wong, R.W. S. Poon, J.J. Cai, W.K. Luk, et al. 2005. Characterization and complete genome sequence of a novel coronavirus, coronavirus HKU1, from patients with pneumonia. Journal of Virology 79 (2): 884-895. https://doi.org/10.1128/JVI. 79.2.884-895.2005

Woo, P.C.Y., S.K.P. Lau, C.S.F. Lam, K.K.Y. Lai, Y. Huang, P. Lee, G.S.M. Luk, K.C. Dyrting, K.H. Chan, and K.Y. Yuen. 2009. Comparative analysis of complete genome sequences of three avian coronaviruses reveals a novel group $3 \mathrm{C}$ coronavirus. Journal of Virology 83 (2): 908-917. https://doi.org/10.1128/jvi.01 977-08.

Woo, P.C.Y., S.K.P. Lau, C.S.F. Lam, C.C.Y. Lau, A.K.L. Tsang, J.H.N. Lau, R. Bai, J.L.L. Teng, C.C.C. Tsang, M. Wang, et al. 2012. Discovery of seven novel Mammalian and avian coronaviruses in the genus Deltacoronavirus supports bat coronaviruses as the gene source of Alphacoronavirus and Betacoronavirus and avian coronaviruses as the gene source of Gammacoronavirus and Deltacoronavirus. Journal of Virology 86 (7): $3995-$ 4008. https://doi.org/10.1128/JVI.06540-11.

Woo, P.C.Y., S.K.P. Lau, C.S.F. Lam, A.K.L. Tsang, S.W. Hui, R.Y.Y. Fan, P. Martelli, and K.Y. Yuen. 2014a. Discovery of a novel bottlenose dolphin coronavirus reveals a distinct species of marine mammal coronavirus in Gammacoronavirus. Journal of Virology 88 (2): 1318-1331. https://doi.org/10.1128/JVI.02351-13.

Woo, P.C.Y., S.K.P. Lau, K.S.M. Li, R.W.S. Poon, B.H.L. Wong, H.W. Tsoi, B.C.K. Yip, Y. Huang, K.H. Chan, and K.Y. Yuen. 2006a. Molecular diversity of coronaviruses in bats. Virology 351 (1): 180-187. https://doi.org/10.1016/j.virol.2006.02.041.

Woo, P.C.Y., S.K.P. Lau, U. Wernery, E.Y.M. Wong, A.K.L. Tsang, B. Johnson, C.C.Y Yip, C.C.Y. Lau, S. Sivakumar, J.P. Cai, et al. 2014b. Novel Betacoronavirus in dromedaries of the Middle East, 2013. Emerging Infectious Diseases 20 (4): 560-572. https://doi.org/10.3201/eid2004.131769.

Woo, P.C.Y., S.K.P. Lau, C.C.Y. Yip, Y. Huang, H.W. Tsoi, K.H. Chan, and K.Y. Yuen. 2006b. Comparative analysis of 22 coronavirus $\mathrm{HKU}_{1}$ genomes reveals a novel genotype and evidence of natural recombination in coronavirus $\mathrm{HKU}_{1}$. Journal of Virology 80 (14): 7136-7145. https://doi.org/10.1128/JVI.00509-06.

Wu, Z.Q., L. Lu, J. Du, L. Yang, X.W. Ren, B. Liu, J.Y. Jiang, J. Yang, J. Dong, L.L. Sun, et al. 2018. Comparative analysis of rodent and small mammal viromes to better understand the wildlife origin of emerging infectious diseases. Microbiome 6 (1): 178. https://doi.org/10.1186/s40168-018-0554-9.

Wu, Z.Q., L. Yang, X.W. Ren, G.M. He, J.P. Zhang, J. Yang, Z.H. Qian, J. Dong, L.L. Sun, Y.F. Zhu, et al. 2016. Deciphering the bat virome catalog to better understand the ecological diversity of bat viruses and the bat origin of emerging infectious diseases. The ISME Journal 10 (3): 609-620. https://doi. org/10.1038/ismej.2015.138.

Xiao, K.P., J.Q. Zhai, Y.Y. Feng, N. Zhou, X. Zhang, J.J. Zou, N. Li, Y.Q. Guo, X.B. Li, X. J. Shen, et al. 2020. Isolation of SARS-CoV-2-related coronavirus from Malayan pangolins. Nature 583 (7815): 286-289. https://doi.org/10.1038/s41586-02 0-2313-X.

Yang, L., J.Y. Dai, J. Zhao, Y.F. Wang, P.J. Deng, and J. Wang. 2020a. Estimation of incubation period and serial interval of COVID-19: analysis of 178 cases and 131 transmission chains in Hubei Province, China. Epidemiology and Infection 148: e117. https://doi.org/10.1017/S0950268820001338.

Yang, L., Z.Q. Wu, X.W. Ren, F. Yang, J.P. Zhang, G.M. He, J. Dong, L.L. Sun, Y.F. Zhu, S.Y. Zhang, et al. 2014a. MERS-related Betacoronavirus in Vespertilio superans bats, China. Emerging Infectious Diseases 20 (7): 1260-1262. https:// doi.org/10.3201/eid2007.

Yang, X.L., B. Hu, B. Wang, M.N. Wang, Q. Zhang, W. Zhang, L.J. Wu, X.Y. Ge, Y.Z. Zhang, P. Daszak, et al. 2015. Isolation and characterization of a novel bat coronavirus closely related to the direct progenitor of severe acute respiratory syndrome coronavirus. Journal of Virology 90 (6): 3253-3256. https://doi.org/10.1128/JVl.02582-15.

Yang, Y., L.Y. Du, C. Liu, L.L. Wang, C.Q. Ma, J. Tang, R.S. Baric, S.B. Jiang, and F. Li. 2014b. Receptor usage and cell entry of bat coronavirus $\mathrm{HKU}_{4}$ provide insight into bat-to-human transmission of MERS coronavirus. Proceedings of the National Academy of Sciences USA 111 (34): 12516-12521. https://doi. org/10.1073/pnas.1405889111.

Yang, Y.L., P. Qin, B. Wang, Y. Liu, G.H. Xu, L. Peng, J. Zhou, S.J. Zhu, and Y.W. Huang. 2019. Broad cross-species infection of cultured cells by bat $\mathrm{HKU}_{2-}$ related swine acute diarrhea syndrome coronavirus and identification of its replication in murine dendritic cells in vivo highlight its potential for diverse interspecies transmission. Journal of Virology 93 (24): e01448-e01419. https:// doi.org/10.1128/jvi.01448-19.

Yang, Y.L., J.Q. Yu, and Y.W. Huang. 2020b. Swine enteric Alphacoronavirus (swine acute diarrhea syndrome coronavirus): an update three years after its discovery. Virus Research 285: 198024. https://doi.org/10.1016/j.virusres.2020.1 98024.

Yinda, C.K., S.M. Ghogomu, N. Conceição-Neto, L. Beller, W. Deboutte, E. Vanhulle, P. Maes, M. Van Ranst, and J. Matthijnssens. 2018. Cameroonian fruit bats harbor divergent viruses, including Rotavirus $\mathrm{H}$, bastroviruses, and picobirnaviruses using an alternative genetic code. Virus Evolution 4 (1): vey008. https://doi.org/10.1093/ve/vey008.

Zaki, A.M., S. van Boheemen, T.M. Bestebroer, A.D.M.E. Osterhaus, and R.A.M. Fouchier. 2012. Isolation of a novel coronavirus from a man with pneumonia in Saudi Arabia. The New England Journal of Medicine 367 (19): 1814-1820. https://doi.org/10.1056/NEJMoa1211721.

Zeng, L., E.K. Godeny, S.L. Methven, and M.A. Brinton. 1995. Analysis of Simian hemorrhagic fever virus (SHFV) subgenomic RNAs, junction sequences, and 5' leader. Virology 207 (2): 543-548. https://doi.org/10.1006/viro.1995.1114.

Zeng, Z., T.T. Li, X. Jin, F.H. Peng, N.H. Song, G.Q. Peng, and X.Y. Ge. 2017. Coexistence of multiple genotypes of porcine epidemic diarrhea virus with novel mutant $S$ genes in the Hubei Province of China in 2016. Virologica Sinica 32 (4): 298-306. https://doi.org/10.1007/s12250-017-4021-8.

Zeng, Z.Q., D.H. Chen, W.P. Tan, S.Y. Qiu, D. Xu, H.X. Liang, M.X. Chen, X. Li, Z.S. Lin, W.K. Liu, et al. 2018. Epidemiology and clinical characteristics of human coronaviruses OC43, 229E, NL63, and HKU1: a study of hospitalized children with acute respiratory tract infection in Guangzhou, China. European Journal of Clinical Microbiology \& Infectious Diseases 37 (2): 363-369. https://doi.org/1 0.1007/s10096-017-3144-z

Zhang, J.Q. 2016. Porcine Deltacoronavirus: Overview of infection dynamics, diagnostic methods, prevalence and genetic evolution. Virus Research 226: 71-84. https://doi.org/10.1016/j.virusres.2016.05.028.

Zhang, J.Q., P.J. Timoney, N.J. MacLachlan, and U.B.R. Balasuriya. 2008. Identification of an additional neutralization determinant of equine arteritis virus. Virus Research 138 (1/2): 150-153. https://doi.org/10.1016/j.virusres.2008. 09.003.

Zhang, M.J., D.J. Liu, X.L. Liu, X.Y. Ge, A. Jongkaewwattana, Q.G. He, and R. Luo. 2019. Genomic characterization and pathogenicity of porcine Deltacoronavirus strain CHN-HG-2017 from China. Archives of Virology 164 (2): 413-425. https://doi.org/10.1007/s00705-018-4081-6.

Zhang, Y., J.G. Li, Y. Xiao, J. Zhang, Y. Wang, L. Chen, G. Paranhos-Baccalà, L.L. Ren, and J.W. Wang. 2015. Genotype shift in human coronavirus OC43 and emergence of a novel genotype by natural recombination. The Journal of Infection 70 (6): 641-650. https://doi.org/10.1016/j.jinf.2014.12.005.

Zhou, H., X. Chen, T. Hu, J. Li, H. Song, Y.R. Liu, P.H. Wang, D. Liu, J. Yang, E.C. Holmes, et al. 2020a. A novel bat coronavirus closely related to SARS-CoV-2 contains natural insertions at the S1/S2 cleavage site of the spike protein. Current Biology 30 (11): 2196-2203.e3. https://doi.org/10.1016/j.cub.2020.05. 023.

Zhou, L., Q.N. Li, J.N. Su, G.H. Chen, Z.X. Wu, Y. Luo, R.T. Wu, Y. Sun, T. Lan, and J.Y. Ma. 2019. The re-emerging of SADS-CoV infection in pig herds in Southern China. Transboundary and Emerging Diseases 66 (5): 2180-2183. https://doi. org/10.1111/tbed.13270.

Zhou, P., H. Fan, T. Lan, X.L. Yang, W.F. Shi, W. Zhang, Y. Zhu, Y.W. Zhang, Q.M. Xie, S. Mani, et al. 2018. Fatal swine acute diarrhoea syndrome caused by an $\mathrm{HKU}_{2}$-related coronavirus of bat origin. Nature 556 (7700): 255-258. https:// doi.org/10.1038/s41586-018-0010-9.

Zhou, P., X.L. Yang, X.G. Wang, B. Hu, L. Zhang, W. Zhang, H.R. Si, Y. Zhu, B. Li, C.L. Huang, et al. 2020b. A pneumonia outbreak associated with a new coronavirus of probable bat origin. Nature 579 (7798): 270-273. https://doi. org/10.1038/s41586-020-2012-7. 
Zhou, S., M.J. Tang, Y. Jiang, X. Chen, X.Y. Shen, J.M. Li, Y.B. Dai, and J.M. Zou. 2014. Complete genome sequence of a novel infectious bronchitis virus strain circulating in China with a distinct S gene. Virus Genes 49 (1): 152-156. https://doi.org/10.1007/s11262-014-1063-y.

Zhu, N., D.Y. Zhang, W.L. Wang, X.W. Li, B. Yang, J.D. Song, X. Zhao, B.Y. Huang, W. F. Shi, R.J. Lu, et al. 2020. A novel coronavirus from patients with pneumonia in China, 2019. The New England Journal of Medicine 382 (8): 727-733. https:// doi.org/10.1056/NEJMoa2001017.

Zhu, X.Y., S.D. Liu, X.L. Wang, Z.C. Luo, Y.J. Shi, D. Wang, G.Q. Peng, H.C. Chen, L.R. Fang, and S.B. Xiao. 2018. Contribution of porcine aminopeptidase N to porcine Deltacoronavirus infection. Emerging Microbes \& Infections 7 (1): 65. https://doi.org/10.1038/s41426-018-0068-3.

Zirkel, F., A. Kurth, P.L. Quan, T. Briese, H. Ellerbrok, G. Pauli, F.H. Leendertz, W.I. Lipkin, J. Ziebuhr, C. Drosten, et al. 2011. An insect nidovirus emerging from a primary tropical rainforest. mBio 2 (3): e00077-e00011. https://doi.org/1 0.1128/mbio.00077-11.

\section{Publisher's Note}

Springer Nature remains neutral with regard to jurisdictional claims in published maps and institutional affiliations.

Ready to submit your research? Choose BMC and benefit from:

- fast, convenient online submission

- thorough peer review by experienced researchers in your field

- rapid publication on acceptance

- support for research data, including large and complex data types

- gold Open Access which fosters wider collaboration and increased citations

- maximum visibility for your research: over $100 \mathrm{M}$ website views per year

At BMC, research is always in progress.

Learn more biomedcentral.com/submissions 